\title{
El informe especial derivado de los hechos de malversación en Cuba: pautas para su perfeccionamiento
}

\section{The Derived Special Report of the Facts of Graft on Cuba: Rules for their Improvement}

Liuver Camilo Momblanc* https://orcid.org/0000-0002-1311-095X Juan Carlos Mendoza Pérez** https://orcid.org/0000-0003-3197-9605 http://dx.doi.org/10.21503/lex.v19i28.2322

* Profesor Auxiliar de Derecho Penal, Especialista en Derecho Penal, Especialista en Administración Pública, Licenciado en Contabilidad y Finanzas, Metodólogo de la Dirección de Organización, Planificación y Archivo, Universidad de Oriente, Cuba. Correo electrónico: liuverc@uo.edu.cu, liuvercamilo@nauta.cu

** Profesor Auxiliar de Derecho Civil y Derecho de Obligaciones en el Departamento de Derecho de la Universidad de Guantánamo, Cuba.

Correo electrónico: jcperez@cug.co.cu, juanc1989@nauta.cu

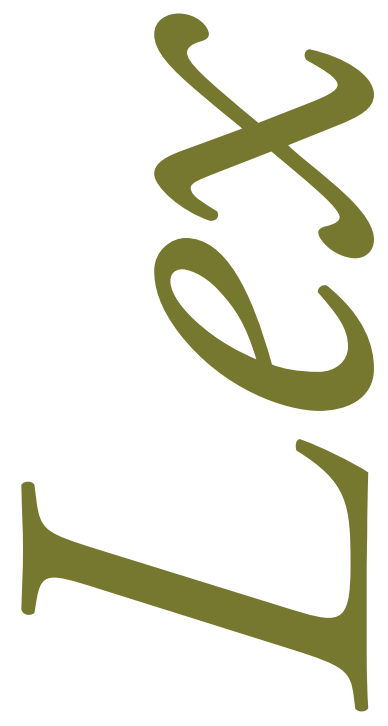




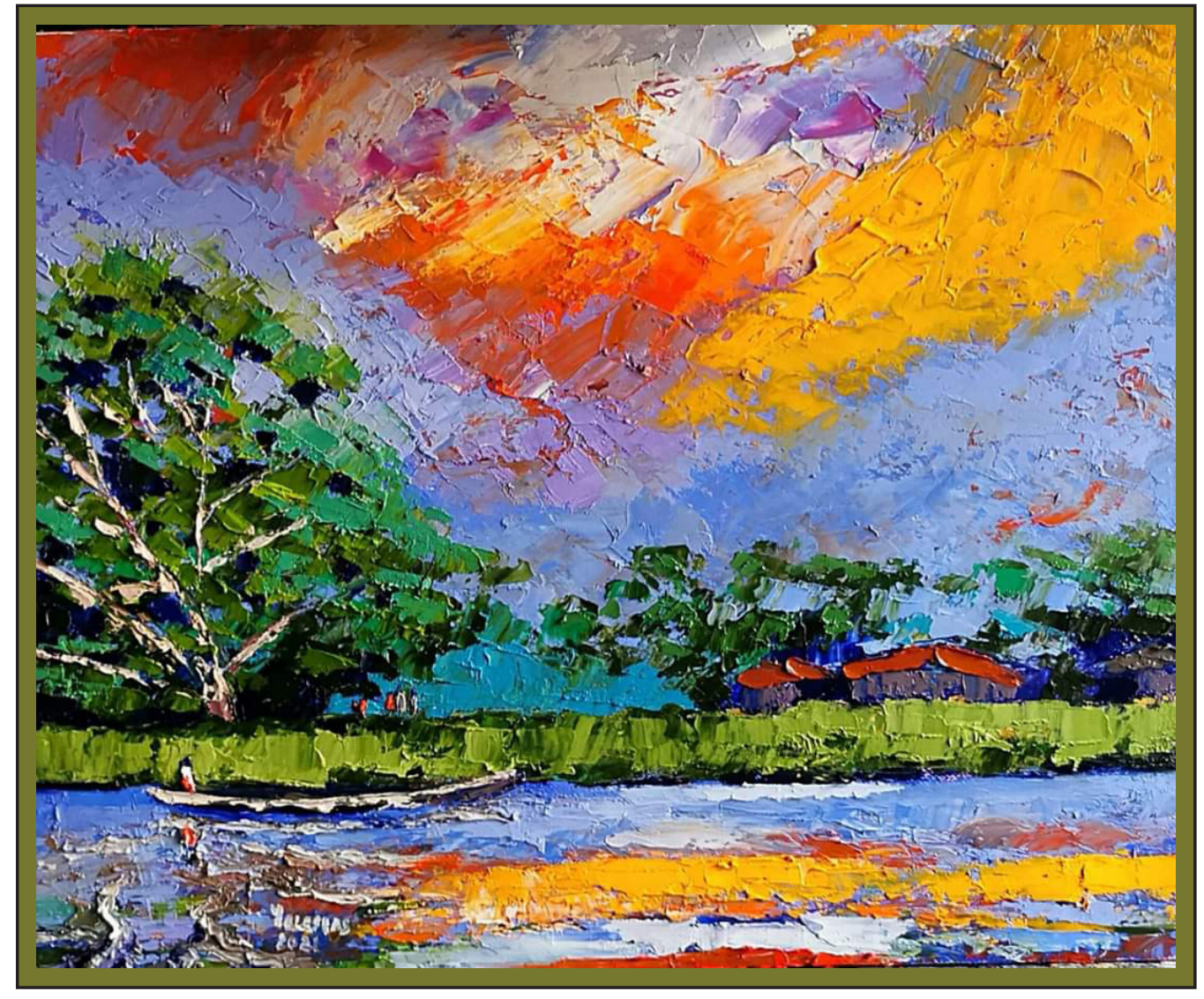

Ribera. Óleo sobre tela 33 X $41 \mathrm{~cm}$.

Javier Yglesias Sánchez (Iquitos, Perú, 1963)

Correo electrónico: javieryglesiassanchez@hotmail.com 


\title{
RESUMEN
}

El Informe Especial se instrumenta en Cuba como un mecanismo dirigido a la erradicación de las deficiencias que entorpecían la tramitación de la documentación necesaria para sustanciar las denuncias formuladas por presuntos delitos económicos y asociados a la corrupción, detectados en acciones de control. Sin embargo, en su elaboración se revelan falencias que obnubilan su cometido. Sobre esta base en el presente artículo se realiza un diagnóstico de las insuficiencias del mismo como elemento de prueba asociado a la investigación de los delitos de Malversación en la provincia Santiago de Cuba y en correspondencia con estas se diseńan pautas para su perfeccionamiento.

Palabras clave: delito económico, acciones de control, hechos de malversación, informe especial.

\begin{abstract}
The Special Report is instrumented in Cuba like a mechanism directed to the eradication of the deficiencies that you/they hindered the procedure of the necessary documentation for substantiate the accusations formulated by presumed economic crimes and associated to the corruption, detected in control actions. However, in their elaboration flaws is revealed that obnubilan its made. On this base article is carried out a diagnosis of the inadequacies of the someone presently as test element associated to the investigation of the crimes of Graft in the county Santiago from Cuba and in correspondence with these rules are designed for its improvement.
\end{abstract}

Key words: economic crime, control actions, made of graft, special report. 


\section{INTRODUCCIÓN}

En la actualidad jurídica internacional, la necesaria búsqueda de mecanismos que perfeccionen la investigación de los hechos delictivos, se ha convertido en una de las cuestiones fundamentales tratadas no solo por estudiosos del derecho. En estos predios, junto a los sujetos principales: fiscalías, tribunales, cuerpos policiales, se suman grupos de análisis, cuerpos de inspectores, auditores, contralores, entre otros, cuya misión común es la prevención y enfrentamiento al delito y la corrupción en aras de la seguridad ciudadana.

No puede ser de otro modo frente a la complejidad de la actividad delictiva que se organiza, perfecciona sus modus operandi y acude incluso a las herramientas tecnológicas de la también intitulada sociedad de la información. Y es que no será eficaz el enfrentamiento al delito si no nos detenemos lo suficientemente a explicar e identificar acciones delictivas racionalmente planificadas. Ya en la época medieval MAQUIAVELO en su obra magna "El Príncipe", expresó que todo rey debe poseer una maquinaria de juzgar perfeccionista, que le asegure defender su reino, y ante todo, parecerse a sus siervos, y a su poder. ${ }^{1}$ En consecuencia, la sociedad moderna demanda de procesos penales con calidad, eficaces, que sirvan de instrumento de vital utilidad para que el Estado enfrente fenómenos que atentan contra su integridad: corrupción, delincuencia económica, tráfico de personas, hechos de extrema violencia, lavado de dinero, entre otros.

Uno de los grandes retos del sistema penal en la actualidad es su eficacia y capacidad para dar respuesta a los nuevos escenarios. En ello, los órganos investigativos requieren de una organización y preparación suficiente, para la búsqueda de los medios de pruebas que permitan ejercer al Ministerio Público o Fiscal -con el respeto a las garantías del imputado y la adecuada racionalidad- la acción penal. Asimismo, al órgano jurisdiccional la formación de su íntima convicción sobre los hechos juzgados y su traducción a través de un fallo de inocencia o culpabilidad.

Los órganos de control y fiscalización de la economía desempeñan en esta dirección un rol esencial, así como el denominado Informe Especial como elemento de prueba de cara al proceso penal. Este es

1. Maquiavelo, El Príncipe. 
resultado de las acciones de control en las que durante su ejecución se detecte un hecho presuntamente delictivo. Ello justifica la elección de: El Informe Especial Derivado de los hechos de Malversación en Cuba. Pautas para su perfeccionamiento, como título de esta investigación.

Una mirada a la producción científica muestra, tanto en nuestros predios como fuera de ellos, un abundante patrimonio bibliográfico sobre este tema; pero las investigaciones realizadas se enfocan más bien desde una perspectiva criminológica ${ }^{2}$ o sustantiva hacia los dominios del Derecho Penal Económico. ${ }^{3}$ Así, sobre el Informe Especial como elemento de estudio solo encontramos como antecedentes investigativos dos tesis en opción al título de Especialista en Derecho Penal. La primera, ${ }^{4}$ si bien particulariza en la cuestión referida a la probanza del delito de Malversación, se limita a relevar la importancia del Informe Especial a partir del diagnóstico de las deficiencias en su elaboración. En tanto la segunda, ${ }^{5}$ desde el enfoque general de los delitos económicos, realiza propuestas del perfeccionamiento de este instrumento circunscritas al orden normativo.

Teniendo en cuenta el comportamiento de la radicación del delito de Malversación en Santiago de Cuba y las deficiencias existentes en la elaboración del Informe Especial como elemento de prueba que impacta en la calidad y celeridad de la investigación criminal y el proceso penal, retomamos su investigación. Esta vez en un ámbito espacial diferente al de las tesis precedentes y en aras de formular una propuesta que integre además de la dimensión normativa, la de recursos humanos y de organización.

Objetivo general: Fundamentar, a partir de un análisis teórico-práctico y exegético, la necesidad del perfeccionamiento del Informe Especial como elemento de prueba en aras de un mayor esclarecimiento y celeridad de los procesos penales seguidos por delitos de Malversación en la provincia Santiago de Cuba.

\section{II. ÓRGANOS Y ACCIONES DE CONTROL DE LA ECONOMÍA DE CARA AL PROCE- SO PENAL EN CUBA}

Entre las distintas causas que propician la comisión de delitos que lesionan el "orden económico"6

2. En la doctrina extranjera, esta temática ha sido abordada con mayor amplitud, sobre todo a partir de 1939 con la conocida teoría del "delito de cuello blanco" de Edwin Sutherland. También, entre otros criminólogos que dedicaron parte de sus investigaciones científicas a su estudio, se destacan Alessandro Baratta, Emile Durkheim, Robert Merton y Klaus Tiedeman, entre otros. Baratta, Criminología crítica y crítica del derecho penal: introducción a la sociología jurídico penal; King Merton, Teoría Social y Estructura Social; Tiedemann, "Abuso del poder económico y comercio internacional. Dos problemas básicos de la delincuencia económica»; Durkheim, La División del Trabajo Social y el Suicidio. En Cuba destaca la obra de De la Cruz Ochoa, Crimen Organizado, Tráfico de Drogas, Lavado de Dinero y Terrorismo.

3. Grillo Longoria, Los delitos en especie; De la Cruz Ochoa, Delitos contra la economía nacional. Asimismo., un importante número de tesis del nivel de posgrado que en su conjunto revelan la importancia y pertinencia del tema.

4. Navarro Borges, «El informe especial. Utilidad probatoria para el delito de malversación». Tesis

5. Rodríguez Carrazana, «El Informe Especial. Su repercusión en la actividad probatoria en los delitos económicos». Tesis

6. Vid. De la Cruz Ochoa, «Delitos contra la economía nacional», en Derecho Penal Especial, (La Habana: Felix Varela 2003) 225-52. 
se encuentra el descontrol que esencialmente se produce tras el incumplimiento de las normas que disponen el funcionamiento de las actividades económicas y el cuidado efectivo de los bienes, recursos materiales y financieros existentes en una entidad. ${ }^{7}$ Entre otras razones, es esta una de las que motiva el fortalecimiento de los mecanismos de control en este ámbito en aras de la corrección de las irregularidades que favorecen la ocurrencia de delitos económicos. En sentido amplio, son aquellas conductas capaces de poner en peligro la vida económica como orden general; comportamientos descritos en las leyes que lesionan la confianza en el orden económico vigente o de alguna de sus instituciones en particular y, por tanto, ponen en peligro la propia existencia y las formas de actividad de ese orden socioeconómico. ${ }^{8}$

$\mathrm{Al}$ atentar contra la estabilidad de un sistema económico, cualquiera que este sea, ${ }^{9}$ son objeto de especial preocupación social, judicial y académica. No es por ello de extrańar que cada vez sean más los minuciosos y brillantes estudios doctrinales que se realizan en aras de formular propuestas que permitan mitigar, con nuevas acciones legislativas o con mejores lecturas de los tipos penales existentes, la delincuencia económica. ${ }^{10}$ En este sentido, el instrumento de control económico del que más se vale el Derecho Penal es la auditoría, la cual desempeña un importante papel en la detección y el esclarecimiento de los delitos económicos. También resulta un mecanismo probatorio fundamental en el proceso penal e influye directamente en la eficiencia económica y en la probidad de los agentes, funcionarios y directivos que participan en las actividades socioeconómicas. ${ }^{11}$ La American Accounting Association al referirse a esta ha acuñado que:

La auditoría es un proceso sistemático para obtener y evaluar de manera objetiva las evidencias relacionadas con informes sobre actividades económicas y otros acontecimientos relacionados. El fin del proceso consiste en determinar el grado de correspondencia del contenido informativo con las evidencias que le dieron origen, así como determinar si dichos informes se han elaborado observando principios establecidos para el caso. ${ }^{12}$

Para MEJÍAS RODRÍGUEZ, "la auditoría se identifica como una técnica de control, dirigida a valorar el control interno y la observancia de las normas generales de contabilidad. Comprende además un examen independiente de los registros de contabilidad y otras evidencias relacionadas con una entidad para apoyar la opinión experta e imparcial sobre la confiabilidad de los estados financieros". ${ }^{13}$ Existen diferentes tipos de auditorías aplicables en el marco de determinadas materias, temáticas o actividades económicas, así como en virtud del interés y los resultados que se pretenda alcanzar con ella. Así, por ejemplo, se conocen entre otras, la auditoría gubernamental, la especial, de estados financieros, la fiscal, operacional, temática, de sistemas, de seguimiento, de cumplimiento y las tecnológicas. ${ }^{14}$

7. Mejías Rodríguez, Derecho Penal Económico, 75.

8. Cervini, «Derecho penal económico, perspectiva integrada»; Mejías Rodríguez, Derecho Penal Económico, 44.

9. De la Cruz Ochoa, «Delitos contra la economía nacional», op.cit., 226.

10. Cfr. Mata Barranco et al., Derecho penal económico y de la empresa, 37.

11. Mejías Rodríguez, Derecho Penal Económico, 77.

12. Citado en: Cook y Winkle, Auditoría, 1:5.

13. Mejías Rodríguez, Derecho Penal Económico, 77.

14. Ibid., 77-78. 
En el desarrollo de los procesos vinculados al "control interno", ${ }^{15}$ los órganos del Estado realizan una labor fundamental. La necesidad de preservar las finanzas y los bienes patrimoniales públicos, utilizando el control económico y administrativo como el medio más eficaz, propició que se creara en Cuba primeramente como organismo de la Administración Central del Estado mediante el Decreto-Ley No. 219 de 25 de abril de 2001, el Ministerio de Auditoría y Control. ${ }^{16}$ Este desempeñó un rol trascendente en la detección y fiscalización de las actividades económicas, revelando, denunciando y corrigiendo irregularidades, indisciplinas y manifestaciones delictivas acontecidas en organismos e instituciones públicas y privadas.

Más tarde con las experiencias acumuladas y el llamado de la Asamblea General de las Naciones Unidas en la Convención contra la corrupción, firmada por nuestro país el 9 de diciembre de 2005 y ratificada en febrero de 2007, se instituyó mediante la Ley No. 107 de 1 de agosto de 2009, la Contraloría de la República de Cuba. ${ }^{17}$ Con la aprobación de la nueva Constitución de la República se consagra este órgano en el Título VI referido a la estructura del Estado donde se ratifica como misión fundamental la de velar por la correcta y transparente administración de los fondos públicos y el control superior sobre la gestión administrativa. ${ }^{18}$ En razón a ello propone la política integral del Estado en materia de preservación de las finanzas públicas y el control económico-administrativo. Una vez que es aprobada, le corresponde dirigir, ejecutar y comprobar su cumplimiento. De igual forma dirige metodológicamente y supervisa el Sistema Nacional de Auditoría y ejecuta las acciones que considere necesarias con el fin de velar por la correcta y transparente administración del patrimonio público; así como la prevención y lucha contra la corrupción. ${ }^{19}$

Por otra parte, la Fiscalía General de la República, acompañando su misión de ejercer la acción penal ante los tribunales de justicia en los llamados delitos de acción pública, ${ }^{20}$ también realiza entre sus diversas funciones, la de comprobar el estado de la legalidad en los órganos y organismos del Estado a través de las verificaciones fiscales. Al amparo de la Ley No. 83 de 1997, las verificaciones fiscales constituyen un instrumento eficaz para comprobar el cumplimiento del objeto social de las entidades, el uso y destino de los recursos materiales y financieros, el cumplimiento de las obligaciones tributarias y de las demás normas legales. ${ }^{21}$

15. Vid. Cuba. Contraloría General de la República de Cuba, «Resolución No. 60 "Normas del Sistema de Control Interno"».

16. Cuba. Consejo de Estado, «Decreto Ley No. 219 “Del Ministerio de Auditoría y Control”».

17. Vid. Cuba. Asamblea Nacional del Poder Popular, «Ley No. 107 "De la Contraloría General de la República de Cuba"».

18. Vid. art. 160 «Constitución de la República de Cuba».

19. Cuba. Asamblea Nacional del Poder Popular, «Ley No. 107 “De la Contraloría General de la República de Cuba”.

20. Vid. art. 156 «Constitución de la República de Cuba».

21. Cuba. Asamblea Nacional del Poder Popular, «Ley No. 83 “De la Fiscalía General de la República”». 
Las verificaciones fiscales se definen como las distintas acciones y diligencias que realizan los fiscales con auxilio de especialistas y peritos, como un método de control para comprobar el cumplimiento de la Constitución, las leyes y demás disposiciones legales vigentes en los organismos del Estado, las entidades económicas y sociales, formulando los pronunciamientos que resulten procedentes. Entre sus objetivos se encuentra el de comprobar el cumplimiento de las disposiciones relativas al objeto social, el uso, destino y preservación de los recursos materiales y financieros; contribuir a la protección de los bienes de propiedad del Estado y asegurar que se utilicen de acuerdo con los fines para los que fueron destinados o producidos; velar por el uso del capital social del Estado en las entidades jurídicamente privadas en las que tenga participación; prevenir, descubrir y enfrentar las manifestaciones de corrupción administrativa; contribuir a fortalecer la disciplina estatal, determinar la responsabilidad laboral, material o penal de los infractores de la ley, en los casos que así se compruebe, y comprobar y exigir la erradicación de las violaciones detectadas. $^{22}$

La Contraloría y la Fiscalía, aunque ocupan lugares privilegiados como órganos de control, no son los únicos que ejercen funciones fiscalizadoras. La sociedad cubana en los últimos tiempos se viene auxiliando de otras instituciones y organismos para evaluar el comportamiento y cumplimiento de las políticas económicas y el soporte normativo que las contempla, siendo un ejemplo de ello los órganos locales del poder popular, ${ }^{23}$ los cuales han establecido mecanismos y aparatos de supervisión sobre las personas naturales vinculadas a sectores económicos e instituciones y entidades económicas estatales, a través del sistema de inspección estatal de los organismos de la Administración Central del Estado. ${ }^{24}$ Asimismo, a partir de las deficiencias que entorpecían la tramitación de la documentación que se requiere para sustanciar los procesos de las denuncias formuladas por presuntos delitos económicos y asociados a la corrupción como resultado de acciones de control, se puso en vigor el 5 de mayo de 2005, la Resolución Conjunta, Ministerio del Interior-Fiscalía General de la República, en virtud de la cual se crean los Grupos de Análisis y se estableció el procedimiento para la formulación y tramitación de las denuncias en estos casos.

Sobre la base del perfeccionamiento del trabajo de estos grupos, actualmente se definen como un equipo multidisciplinario, conformado por instructores penales especializados en el enfrentamiento a la delincuencia económica, oficiales operativos del Ministerio del Interior (MININT) y fiscales. Como función principal tiene la de examinar y dictaminar los informes especiales sobre presuntos hechos delictivos derivados de auditorías, otras acciones de control, verificaciones o investigaciones fiscales, conjuntamente con las evidencias que los sustentan, antes de proceder a la tramitación penal de la denuncia. ${ }^{25}$ Se dispone que el Grupo de Análisis, después de recibir el Informe Especial y la documentación

22. Vid.Artículos del 22 al 23 de la Ley No. 83 de 1997 de la Fiscalía General de la República de Cuba.

23. Entre ellos tenemos la Dirección Integral de Supervisión conocida por sus silgas DIS.

24. Mejías Rodríguez, Derecho Penal Económico, 82.

25. Contraloría General de la República, «Resolución No. 480/2017». 
primaria que lo sustenta, tenga un término de diez días para su análisis. De estimar que deben precisarse elementos expuestos en el informe o que las evidencias que lo sustentan son insuficientes a los efectos del proceso penal, lo devuelve a quien practicó la acción de control, mediante el correspondiente dictamen. La respuesta a lo interesado se realiza por los contralores, auditores o especialistas actuantes, en el término legalmente establecido y se considera, a todos los efectos legales, como ampliación del informe inicialmente presentado, entonces devenido en informe pericial pues estos sujetos concurren al proceso en calidad perito. ${ }^{26}$

En este sentido, como reza la Resolución 480 de la Contraloría General de la República de Cuba, cuando el contralor, auditor o especialista es citado por el tribunal para comparecer como perito en el acto del juicio oral, debe prepararse y contar con el asesoramiento del jurista correspondiente. Esto con el objetivo de ser instruido respecto a la forma de participar en la vista del juicio oral. También, debe intercambiar al respecto con el fiscal designado para el referido acto y con el instructor del caso, manteniéndose en contacto con la Fiscalía hasta la culminación del proceso para conocer sus resultados. ${ }^{27}$

Como se aprecia, son varios los órganos de control y fiscalización de la economía existente en Cuba, varios son también los sujetos que realizan las acciones de control. Entre ellos destacan los auditores, contralores y especialistas, y aunque el instrumento de control económico del que más se vale el Derecho Penal es la auditoría, todos revisten la misma importancia en este ámbito. De detectarse durante el desarrollo de estas acciones de control un hecho presuntamente delictivo se debe elaborar el Informe Especial. Este desempeña un importante papel en la detección y el esclarecimiento de los delitos económicos del cual el delito de Malversación constituye uno los casos más ilustrativos. Luego el informe junto a la documentación primaria que lo sustenta debe ser examinado por el Grupo de Análisis previo a la formulación de la denuncia. Este resulta un elemento de prueba fundamental de cara al futuro proceso penal, razón por la cual a sus principales coordenadas -surgimiento, contenido y alcance-, dedicamos el próximo epígrafe.

\section{EL INFORME ESPECIAL SOBRE PRESUNTO HECHO DELICTIVO: PRINCIPALES COORDENADAS}

El Informe Especial sobre presunto hecho delictivo es el documento que en principio elaboran los jefes de grupo de la Contraloría General de la República y de las demás unidades organizativas del Sistema Nacional de Auditoría, así como los auditores internos de base, ante la detección en el marco de una acción de control de un hecho que supuestamente reviste características infractoras de las normas penales. Como elemento fundamental en la investigación y probanza de los hechos presuntamente

26. Véase también: Cuba. Contraloría General de la República de Cuba, «Resolución No. 480 "Procedimiento para la tramitación del Informe Especial en las acciones de control en que se detecte un presunto hecho delictivo y en las solicitadas por los Tribunales Populares, la Fiscalía general de la República y el Ministerio del Interior”».

27. Vid. Artículo 34 en: Contraloría General de la República, «Resolución No. 480/2017». 
delictivos, expresa de forma razonada el juicio profesional del contralor, auditor o especialista, sobre la base de las evidencias obtenidas. También incluye, en los casos que proceda, el resultado del trabajo realizado por los expertos.

Una mirada a la génesis del Informe Especial nos remite al Decreto-Ley No. 159 del Consejo de Estado de fecha 8 de junio de 1995. Antes de su puesta en vigor ya se informaba a los órganos competentes de los presuntos hechos delictivos que se detectaban a través del trabajo de auditoría. No obstante, fue con su adopción cuando por vez primera se estableció la obligatoriedad de los auditores jefes de grupo de presentarlo ante las autoridades competentes cuando en el desempeño de sus funciones detectasen acciones u omisiones presumiblemente delictivas. En estos casos también se exigió acompañar el informe con los documentos probatorios originales ocupados. ${ }^{28}$

Al crearse el Ministerio de Auditoría y Control por el Decreto Ley No. 219 de 21 de abril de 2001, ${ }^{29}$ se reafirmó lo dispuesto anteriormente. A partir de ese momento este organismo de la Administración Central del Estado sería el encargado de dirigir, ejecutar y controlar la aplicación de la política del Estado y del Gobierno en materia de auditoría gubernamental, fiscalización y control gubernamental; así como de regular, organizar, dirigir y controlar metodológicamente, el Sistema Nacional de Auditoría. ${ }^{30}$ Por tanto, el Comité Ejecutivo del Consejo de Ministros adoptó el Acuerdo No. 4045 de fecha 31 de mayo de ese propio año ${ }^{31}$ en el que define los objetivos, funciones, atribuciones específicas y estructura del extinto Ministerio de Auditoría y Control. El numeral 11 del segundo apartado del Acuerdo, establece que dicho Ministerio tiene entre sus funciones y atribuciones específicas la de trasladar los dictámenes que resulten de su actividad a los órganos correspondientes, ante los casos que evidencien la comisión de presuntos hechos delictivos. ${ }^{32}$

Aproximadamente dos años más tarde, el 20 octubre del 2003 el Ministerio de Auditoría y Control emitió la Resolución 320. Como resultado de las actividades de este Ministerio y del Sistema Nacional de Auditoría se detectaban presuntos hechos delictivos y fue necesaria la instrumentación de los procedimientos que establecieran la documentación a presentar ante las autoridades correspondientes cuando en el ejercicio de una acción de control se descubrieran acciones u omisiones de esta naturaleza. ${ }^{33}$ Fue con esta resolución cuando se establece en una normativa específica las exigencias en relación al contenido y alcance del Informe Especial. La experiencia acumulada durante su aplicación demandó

28. Vid. Artículo 17 en: Cuba. Consejo de Estado, «Decreto-Ley No. 159. De la Auditoría».

29. Actualmente derogado por la Ley No. 107, de fecha 01/08/2009.

30. Cuba. Consejo de Estado, «Decreto Ley No. 219 "Del Ministerio de Auditoría y Control”».

31. Derogado por la Ley No. 107, de fecha 01/08/2009.

32. Cuba. Comité Ejecutivo del Consejo de Ministros, «Acuerdo no. 4045. “Objetivo, funciones, atribuciones específicas y estructura del Ministerio de Auditoría y Control"».

33. Cuba. Ministerio de Auditoría y Control, «Resolución No. 320 "Procedimientos para la presentación y tramitación del Informe Especial"» 
que el 23 de febrero del 2005 el Viceministro Primero de dicho organismo emitiera una Nota Aclaratoria en aras de lograr una mejor confección de este instrumento y afianzar su utilidad probatoria para el proceso penal.

En virtud de la experiencia acumulada durante la aplicación de la Resolución No. 320, así como de la Nota Aclaratoria del Viceministro Primero del Ministerio de Auditoría y Control, fue necesario proceder a la promulgación de una nueva disposición jurídica, que integrase el contenido de ambas, atemperándola a la situación actual y a otras disposiciones jurídicas vigentes vinculadas con el tema. Bajo estos presupuestos, en el 2007 dicho Ministerio emitió la Resolución 248. ${ }^{34}$ En ella se aprueba el procedimiento para la elaboración, presentación, tramitación del Informe Especial sobre presunto hecho delictivo y seguimiento de las acciones para su esclarecimiento y procesamiento, cuando se detectan en las acciones de control que realizan los auditores del Sistema Nacional de Auditoría.

Sin embargo, el progreso alcanzado en la actividad de preservación de las finanzas públicas y el incremento del control económico administrativo; así como la firma (9 de diciembre de 2005) y ratificación (9 de febrero de 2007) por nuestro país de la Convención de las Naciones Unidas contra la Corrupción, entre otros factores, justificaron la necesidad de la creación de la Contraloría General de la República de Cuba. Respondiendo a lo estipulado en la citada Convención, adoptada por la Asamblea General de las Naciones Unidas el 31 de octubre de 2003, se creó en el 2009 este órgano estatal encargado de la lucha contra la corrupción, con la independencia necesaria, de conformidad con los principios fundamentales de nuestro ordenamiento jurídico para desempeñar sus funciones de manera eficaz y sin ninguna influencia indebida. ${ }^{35}$

En el reglamento de la Ley No. 107 de la Contraloría General de la República, se establece que entre las funciones y atribuciones de los auditores y contralores de este órgano se encuentra la de elaborar el Informe Especial cuando se detecten hechos presuntamente delictivos. En estos casos el informe se supervisa técnica y legalmente por su jefe inmediato superior y se presenta a la autoridad competente. Esto, sin embargo, no sustituye la responsabilidad de la administración de formular la denuncia. ${ }^{36}$ De esta forma se ratifica el rol de este instrumento y la responsabilidad de la administración de formular la denuncia en estos casos.

No obstante, a consecuencia de los cambios operados con la creación de la Contraloría General de la República y en consideración a la experiencia adquirida por este órgano y el resto de las unidades

34. Cuba. Ministerio de Auditoría y Control, «Resolución No. 248 "Procedimiento para la Elaboración, Presentación, Tramitación del Informe Especial sobre presunto hecho delictivo y Seguimiento de las acciones para su esclarecimiento y procesamiento, cuando se detectan en las acciones de control que realizan los auditores del Sistema Nacional de $\mathrm{Au}$ ditoría”». Esta deroga la Resolución No. 320, de 20 de octubre de 2003, dictada por la Ministra de Auditoría y Control y deja sin efecto legal, la carta firmada por el Viceministro Primero del consignado Organismo, el 23 de febrero de 2005. 35. Cuba. Asamblea Nacional del Poder Popular, «Ley No. 107 "De la Contraloría General de la República de Cuba”». 36. Vid. Artículo 26-e) en: Cuba. Consejo de Estado, «Acuerdo. Reglamento de Ley No. 107 “De la Contraloría General de la República de Cuba"». 
organizativas que conforman el Sistema Nacional de Auditoría, en la aplicación de la Resolución No. 248 dictada por la ministra del extinto Ministerio de Auditoría y Control, se decidió su actualización. También, se justipreció necesario armonizar e integrar los aspectos fundamentales concernientes a la actuación a seguir por contralores, auditores y especialistas en las acciones de control en las que se detectase presunto hecho delictivo. Asimismo, en las que se realizan a solicitud de los Tribunales Populares, la Fiscalía General de la República y el Ministerio del Interior, a fin de contribuir a perfeccionar el enfrentamiento de los delitos económicos y la corrupción. Todo ello mediante la adopción de una herramienta de trabajo que coadyuvara a un mejor y más eficaz desempeño de los profesionales de la auditoría que participan en la investigación de estos hechos, al tiempo que garantizara su adecuado ejercicio. ${ }^{37}$

El 4 de diciembre de 2017 se emite la Resolución 480 de la Contraloría General de la República que aprueba el "Procedimiento para la tramitación del Informe Especial en las acciones de control en que se detecte un presunto hecho delictivo y en las solicitadas por los Tribunales Populares, la Fiscalía General de la República y el Ministerio del Interior”. El mismo, siguiendo los postulados de sus precedentes, tiene como objetivo regular los elementos metodológicos a observar en la elaboración, presentación y seguimiento del informe. También los aspectos fundamentales de la actuación a seguir por contralores, auditores y especialistas de la Contraloría General de la República y demás auditores del Sistema Nacional de Auditoría, en las acciones de control donde se detecte un presunto hecho delictivo, así como en las solicitadas por los Tribunales Populares, la Fiscalía General de la República y el Ministerio del Interior, autoridad facultada, para reunir y presentar las evidencias que sustenten hechos de esta naturaleza. ${ }^{38}$

Luego de este recorrido en el orden histórico-legislativo en torno al Informe Especial, consideramos necesario, en apretada síntesis, valorar su naturaleza según los postulados de la actividad probatoria. En esta tesitura se cuestiona su legitimidad para ser utilizado como material probatorio. Asimismo, y sobre todo, la mayor polémica radica en la determinación del tipo de actividad procesal que debe ser desplegada para lograr el ingreso de este elemento de prueba en el proceso penal. Se discute si se realiza a través de la prueba documental o como prueba pericial, toda vez que el inadecuado manejo de su naturaleza jurídica se traduce en una razón de afectación a la calidad del proceso, entendida también como la forma en que este informe que lo antecede ingresa a él.

El primer gran problema es que este instrumento es anterior al proceso penal y en este ámbito no ha de justipreciarse nada que no esté hecho para él. Sobre la base de este informe el Grupo de Análisis toma la decisión de radicar denuncia, aplicar responsabilidad material o su devolución para subsanar errores

37. Cuba. Contraloría General de la República de Cuba, «Resolución No. 480 "Procedimiento para la tramitación del Informe Especial en las acciones de control en que se detecte un presunto hecho delictivo y en las solicitadas por los Tribunales Populares, la Fiscalía general de la República y el Ministerio del Interior”».

38. Contraloría General de la República, «Resolución No. 480/2017» 
y/o ampliarlo. Constituye el sustento probatorio esencial sobre el cual se instruye el proceso penal. Sin embargo, a pesar de ser confeccionado por auditores, contralores o especialistas que en su momento pudieran fungir como peritos en el acto del juicio oral, no se trata en el momento de su obtención de una prueba pericial stricto sensu.

El dictamen pericial, conforme dispone la Ley de Procedimiento Penal cubana, ${ }^{39}$ se propone cuando para conocer o apreciar algún hecho en la causa se necesiten conocimientos especializados sobre un tema determinado de orden científico, artístico, técnico o práctico. A contrario sensu, el Informe Especial se elabora por mandato de una norma extraprocesal ${ }^{40}$ y su objeto lo constituye un hecho que se presume delictivo. En él no se relacionan las operaciones realizadas por el auditor, contralor o especialista, sino el presunto hecho y las circunstancias que giran a su alrededor. El dictamen pericial por lo general se utiliza para esclarecer un hecho determinado, mientras que este informe contiene un hecho presuntamente delictivo que debe ser probado. En consecuencia, más aceptable resulta, al constituir el informe un documento, la valoración de su naturaleza como medio de prueba documental.

A partir de esta problemática se considera que para adoptar una decisión sobre su naturaleza hay que partir de la determinación de dónde radica la razón de suficiencia probatoria. Si del resto del material probatorio que se asocia al informe resulta claro el hecho y la intervención en el de los sujetos implicados, se puede usar como la tradicional prueba documental. Sin embargo, si este se presenta con contradicciones con el resto del material probatorio que deben someterse a debate para ganar en claridad en la construcción fáctica del hecho, entonces es aconsejable la intervención del perito para interrogarlo sobre su contenido y esclarecer tales contradicciones. El despeje de esta situación particular es lo que aportaría luces sobre su condición como medio de prueba. Se trata de la determinación del elemento en el cual se visualiza la razón de suficiencia probatoria. Si basta con el contenido del documento que por sí solo resulta esclarecedor, entonces se aporta como la tradicional prueba documental pues siempre en estos casos la otra forma es la que se presenta más compleja. Ello porque, la Ley procesal no establece que el medio de prueba es el informe sino el dictamen pericial. Es cierto que este debe documentarse, pero según la forma y exigencias que dispone la ley no satisfechas en el caso del Informe Especial.

También se cuestiona la citación en condición de perito del auditor o equipo que elaboró el Informe Especial por las afectaciones que ello supone al principio de legalidad. Cuando se hace comparecer en el proceso penal a estos sujetos ya han discutido y consensuado el informe en el Grupo de Análisis. Por tanto, en principio, lo que se expone en el plenario no es solo el resultado de sus percepciones, juicio y valoraciones a nivel de su conciencia. También es expresión de las valoraciones realizadas por ese equipo multidisciplinario que operó sobre su conciencia. Por lo que podemos afirmar que la etapa de la actividad probatoria en la que se suscitan las mayores dificultades relacionadas con el Informe Especial desde el punto de vista teórico-doctrinal y práctico es la de acumulación y proposición.

39. Vid. artículo 200 y ss., en: Rivero García, “Ley de Procedimiento Penal”, Ley no. 5 de 13 de agosto de 1977 (Anotada y concordada con las Disposiciones del CGTSP).

40. Vid. Contraloría General de la República, «Resolución No. 480/2017». 
En otro orden, la forma y contenido de estos informes resultan requisitos de obligada observancia para su elaboración y eficacia probatoria. Se trata de un documento que formaliza los resultados exhaustivamente obtenidos por contralores, auditores y especialistas en las verificaciones y trabajos realizados para el esclarecimiento de un presunto hecho delictivo. Es por ello que en las próximas líneas se hará referencia, más que al procedimiento asociado a su tramitación, a sus principales invariantes formales y de contenido.

La Resolución 480 de la Contraloría General de la República en su sección segunda del capítulo tres establece los requisitos y formalidades esenciales del Informe Especial. En esa dirección, amén de las subdivisiones que dispone, consideramos que esencialmente lo estructura en encabezamiento, contenido y anexos. ${ }^{41}$ Sin embargo, a pesar de su importancia, opinamos que una norma cuyo objetivo declarado, entre otros, es regular los elementos metodológicos a observar en la elaboración de este informe, se limita a describir en apretada síntesis y a veces solo a relacionar los aspectos de su contenido.

Como es lógico, el alto grado de generalidad-abstracción y vaguedad de que adolece la norma en la definición de algunos de los aspectos del informe, genera inconvenientes que afectan la posterior tramitación de los procesos que sustenta. Por ello, remitimos a la Resolución 480 en su sección segunda del capítulo tres para conocer los elementos del informe y preferimos relacionar aquí aquellas cuestiones que consideramos deficiencias en la concepción normativa.

En primer orden tenemos que el artículo 21 de la citada norma al establecer los requerimientos para la confección del encabezamiento del Informe Especial no exige la precisión del periodo analizado en la acción de control. Esto resulta de vital importancia para orientar el espacio temporal en el cual se circunscribe el presunto hecho delictivo. Sobre todo cuando se trata, como en los supuestos de malversación, de delitos en los que debe tenerse especial cuidado de comprobar que el periodo que abarque la comisión de los hechos se encuentre comprendido dentro del cual su comisor fungió como responsable de la entidad afectada.

También se aprecia que en el epígrafe 21.2 bajo el título de contenido, expresión de una inadecuada técnica legislativa, se mezclan como elementos que integran la introducción del Informe Especial la caracterización de la entidad, objetivos trazados y breve descripción del presunto hecho delictivo. Esto genera confusión e incertidumbres en cuanto al alcance de dichos aspectos debiendo el redactor de la norma separarlos por incisos o subtítulos y explicitar su contenido.

En el epígrafe 21.2.2 se ubica el desarrollo, que a nuestro juicio debe comprender esencialmente solo los incisos a), b) y c), en tanto el resto funcionarían como epígrafes independientes, amén de que algunos de ellos deberían fusionarse en uno solo. Finalmente, no debe faltar en el informe la descripción de manera cuidadosa de la documentación primaria revisada para ejecutar la acción de control en

41. bid. 
aras de una mejor comprensión del hecho por los instructores penales, fiscales y jueces. Sin embargo, este particular fue omitido por el redactor de la norma. De tal manera no existe duda de que estamos ante un precepto defectuoso, de límites y bordes imprecisos, que dificulta su interpretación y aplicación por parte de los sujetos que realizan las acciones de control y detectan la comisión de presuntos hechos delictivos.

Una disposición normativa de redacción ambigua da lugar a incertidumbres, por tanto, debe ser revisada y enmendada para su correcta aplicación. Aunque se prevé en ella la revisión del informe por un jurista previo a su presentación al Grupo de Análisis, ${ }^{42}$ quien debe certificar su correcta confección y/o dictaminar sobre los aspectos que incumple, persisten dificultades en la elaboración y presentación de estos informes especiales. Ello afecta la realización de las valoraciones para su correcta utilización en el contexto del proceso penal. En este sentido, impactan en la celeridad de estos procesos debido a las devoluciones que se ven conminados a realizar dichos grupos a los contralores, auditores y especialistas en función de su ampliación y/o corrección. La necesidad de identificar dichas dificultades en aras de la construcción de una propuesta que contribuya a su erradicación y con ello a la celeridad y esclarecimiento de los hechos de malversación, justifica el desarrollo del diagnóstico que se presenta en el epígrafe siguiente.

\section{EL INFORME ESPECIAL EN LOS CASOS DE MALVERSACIÓN. PRINCIPALES PRO- BLEMÁTICAS}

La investigación del delito de Malversación por las singularidades que caracterizan a esta figura delictiva y sus comisores se torna complejo. En estos casos los rastros no son igual de tangibles y evidentes que en otros hechos socialmente peligrosos. Ello supone obstáculos a las autoridades que deben esclarecerlos. De esta forma se revela la importancia del Informe Especial, cuyas principales coordenadas se expusieron en el epígrafe precedente. Los esfuerzos que se realizan en la actualidad para prevenir, enfrentar y sancionar la corrupción a nivel global, de la cual esta tipicidad delictiva constituye un genuino ejemplo, aun no consiguen los resultados deseados. El último lustro, por fijar un periodo, se ha caracterizado por una mayor visualización de éste fenómeno en diferentes países. En las próximas cuartillas se presenta un diagnóstico de las deficiencias existentes en la elaboración del Informe Especial como elemento de prueba en la investigación de los delitos de Malversación en la provincia de Santiago de Cuba. Los resultados se han agrupado en tres acápites teniendo en cuenta el método o técnica de la investigación empleada para su realización.

42. Vid. Artículos 22.1 y 23.1 en: Cuba. Contraloría General de la República de Cuba, «Resolución No. 480 "Procedimiento para la tramitación del Informe Especial en las acciones de control en que se detecte un presunto hecho delictivo y en las solicitadas por los Tribunales Populares, la Fiscalía general de la República y el Ministerio del Interior”». 


\section{A) Análisis de la literatura gris ${ }^{43}$}

Una mirada, para analizar nuestro entorno más cercano, a las estadísticas contenida en el Sistema Automatizado del órgano de Investigación Criminal y Operaciones conocido como RADICA, permite constatar la incidencia del delito de Malversación. Para ello, se seleccionó como muestra el periodo 2015-2017, advirtiéndose un incremento de los expedientes instruidos por esta figura penal en estos ańos. En el 2015 se iniciaron 59, en el 2016 fueron 73 y 92 en el 2017 para un total de 224 expedientes radicados por la supuesta comisión de un delito de Malversación.

En todos estos casos, ha desempeñado un rol sustancial para su esclarecimiento el Informe Especial. Por otra parte, las propias estadísticas revelan que en este periodo se realizaron 43 devoluciones de estos Expedientes de Fase Preparatoria a la Fiscalía por el Tribunal, así como fueron cuatro las devoluciones de la Fiscalía a la Instrucción Penal. Un análisis de las principales causales que la originaron permitió identificar como regularidad, la falta de claridad del informe exigiéndose su ampliación en relación al esclarecimiento de circunstancias que no fueron determinadas durante la ejecución de la acción de control.

Un estudio de la tramitación de estos procesos nos condujo a concluir que, con independencia de estas devoluciones, las irregularidades surgen desde el instante de la detección del hecho por los especialistas que realizan la acción de control. Son los correspondientes Grupos de Análisis quienes se han visto conminados a la realización de constantes devoluciones de estos informes a través de dictámenes a los especialistas que lo realizan. En la provincia funcionan siete Grupos de Análisis para la evaluación de los presuntos hechos delictivos provenientes de auditorías, comprobaciones económicas u otro tipo de acción de control. Resultado de la revisión de 185 dictámenes realizados, fue posible la identificación de las principales irregularidades que motivan estas devoluciones que inciden en el proceso penal en general.

Las causas más frecuentes de las devoluciones provocan que en muchos casos haya que reformular el Informe Especial en correspondencia con la Resolución 480 de 2017, de la Contraloría General de la República. También por la necesidad de delimitar el período analizado como parte de la acción de control, no contar con la documentación primaria que sustenta los resultados del análisis económico, por carecer de las entrevistas o descargos tomados por los auditores o comprobadores económicos a los implicados en los hechos investigados, por la ausencia de los certificos de cargo, salario, funciones y trayectoria laboral de los presuntos responsables.

Inciden también, las omisiones de los requisitos esenciales relacionados con la no definición del modus operandi utilizado por los implicados, no descripción de las causas y condiciones que propiciaron

43. Se entiende por literatura gris “(...) aquella literatura de difícil acceso por no estar editada comercialmente. Por ejemplo, las memorias, informes internos, publicaciones de gobierno”. Sokol, Búsqueda y recuperación de la información, 48 . 
la ocurrencia del hecho, no individualización de la responsabilidad de los involucrados, así como la no vinculación del hecho descrito con la documentación primaria y anexos. De igual modo se advierte deficiente evaluación de los daños y perjuicios. No se relacionan las normas específicas infringidas, ni se describe el precepto que incide directamente en el hecho. No se incluye el glosario de términos en los casos de que por la actividad específica que realiza la entidad, sea necesario para su adecuada comprensión. También, se advierte falta de calidad en la confección del Informe Especial y documentos presentados a los Grupos de Análisis, así como deficiencias en el accionar de los directivos de las entidades, en el cumplimiento de los términos indicados, para practicar las diligencias y resolverlas oportunamente. Esto genera casos pendientes que se tramitan fuera del término establecido.

Asimismo, se aprecia falta de preparación de los auditores y especialistas que presentan los casos en los diferentes Grupos de Análisis. El jefe de la unidad organizativa a la que pertenecen o se subordinan metodológicamente los contralores, auditores o especialistas actuantes, en la acción de control no informan al Grupo de Análisis que corresponda, tan pronto resulta detectado el presunto hecho delictivo, con vista a obtener el asesoramiento especializado.

Por otra parte, se constatan algunas irregularidades en la revisión de los informes especiales efectuados por los asesores jurídicos, al no detectarse oportunamente insuficiencias que trascienden a la investigación del proceso. Ello, con independencia, de las que son atribuibles a los correspondientes Grupos de Análisis, Instrucción Penal y la Fiscalía en el control de la calidad en la tramitación de estos casos y que generan las devoluciones del Tribunal.

B) Análisis de las encuestas

Con el propósito de conocer las causas que están incidiendo en la calidad de la elaboración del Informe Especial, algunas propuestas para su perfeccionamiento y las opiniones sobre la importancia del mismo en el esclarecimiento de los presuntos hechos de malversación, se utilizó la técnica de encuesta. También para triangular los datos obtenidos resultado del análisis de documentos expuestos en el acápite precedente. Así, por ejemplo, la cantidad de procesos instruidos en el periodo objeto de estudio y las principales deficiencias asociadas a la tramitación de dicho informe. En este último caso, a través de una pregunta abierta en aras de la obtención de la mayor información posible.

La encuesta se aplicó a una muestra de 31 operadores del derecho, quienes trabajan directamente en la presentación, tramitación y/o valoración del Informe Especial. De ellos, 6 (19.4\%) jueces, 6 (19.4\%) fiscales, $11(31.5 \%)$ instructores y 8 (25.8\%) auditores. De conformidad con sus años de experiencia laboral se obtiene una media igual a 14.42 años y la moda es de 18 años con unos valores extremos entre 1 y 30 .

A la primera pregunta: ¿En el ejercicio profesional haz conocido de procesos seguidos por delitos de malversación?, todos los encuestados (100\%) respondieron de forma afirmativa. En relación a (pregunta 2) la frecuencia con que lo habían realizado desde enero el 2015 hasta el presente, 24 (77.4\%) 
expresaron que, con frecuencia, $5(16.5 \%)$ que a veces y $2(6.1 \%)$ que muy pocas veces. Ello no solo otorga valor y confiabilidad al resto de los datos aportados por los encuestados sobre el objeto de la indagación; también resulta coherente con la información estadística que denota el aumento de estos procesos en la provincia Santiago de Cuba.

A la tercera interrogante: ¿Considera que existen dificultades en la tramitación de estos procesos en función de su esclarecimiento?, la mayoría de los encuestados, 28 (90.3\%) sostuvo que sí y solo 3 (9.7\%) opina lo contrario. En consecuencia, al solicitársele en la cuarta pregunta, de haber sido positiva su respuesta en la precedente, la enumeración de tales dificultades, de forma general los primeros relacionan las siguientes:

- Insuficiente preparación de los contralores, auditores, especialistas, instructores penales y fiscales que participan en la investigación y tramitación de estos hechos presuntamente delictivos.

- Deficiencias en el acopio y presentación del material probatorio.

- Falta de documentos primarios originales que tributen al esclarecimiento del hecho.

- Escasa fundamentación de los presuntos hechos delictivos en los Informes Especiales, los que adolecen de omisiones.

- Deficiencias en la calidad y profundidad de las investigaciones, que limita la posibilidad de realizar pronunciamientos respecto a los bienes que forman parte del patrimonio de los implicados.

- Insuficiencias en el seguimiento a los casos pendientes y devueltos por el Grupo de Análisis a contralores, auditores, especialistas que ejecutaron la acción de control.

- Deficiente delimitación del periodo analizado presentándose en ocasiones de manera separadas a pesar de tratarse de los mismos implicados en la misma entidad y adecuada proximidad en el tiempo.

- Deficiente delimitación de los implicados, toma y verificación del descargo de los mismos, así como del esclarecimiento del mecanismo de defraudación.

Asimismo, en relación a las principales deficiencias que han estado presentes en la elaboración de los Informes Especiales de auditoría de los últimos tres ańos asociados al delito de Malversación (pregunta 5), los encuestados consideraron fundamentalmente las siguientes:

- Deficiente determinación de los modus operandi, así como de las causas y condiciones que originaron el presunto hecho delictivo. 
- Deficiente descripción y narración de los hechos con trascendencia a la esfera penal que en ocasiones no se reseńan en función de la documentación o elementos probatorios.

- Incoherencias desde el punto de vista filológico que afectan la comprensión del informe.

- Deficiente revisión por los juristas de las entidades de los Informes Especiales presentados.

- Deficiente depuración de los casos presentados al Grupo de Análisis.

- Incorrecta delimitación de los responsables directos e indirectos.

Respecto al impacto de estas deficiencias en la tramitación y esclarecimiento de los hechos de Malversación (pregunta 6), 11 (35.5\%) lo considera muy alto, 17 (54.8\%) alto y solo 3 (9.7\%) opinan que es bajo. En consecuencia, sobre la importancia que le atribuyen al Informe Especial para el esclarecimiento de estos hechos (pregunta 7), 8 (25.8\%) optaron por otorgarle 4 puntos (alta importancia) mientras que 23 (74.2\%), o sea, la mayoría de los encuestados, lo califica de 5 puntos (muy alta).

Los criterios se manifiestan menos unánimes en relación a la evaluación de la calidad técnica de la norma que establece las exigencias para la presentación y tramitación del Informe Especial (pregunta 8). En este orden, 4 (12.9\%) opina que es muy mala, 8 (25.8\%) mala, 8 (25.8\%) regular, 4 (12.9\%) buena y 7 (22.6\%) muy buena. En cambio (pregunta 9), 29 (93.5\%) de los encuestados consideran que la preparación que actualmente poseen los juristas que participan en la revisión y dictamen del Informe Especial para su presentación al Grupo de Análisis es regular y solo 2 (6.5\%) la evalúa de buena.

Finalmente, en aras de la consecución del perfeccionamiento de la calidad del Informe Especial en los casos de Malversación (pregunta 10), generalmente proponen:

- La realización de cursos de capacitación a los contralores, auditores, especialistas, instructores penales y fiscales que participan en la investigación y tramitación de estos hechos presuntamente delictivos.

- Impartición de cursos de preparación y actualización sobre la práctica a tiempo real (nuevos fenómenos, modus operandi, empleo de tecnología para enmascarar los hechos).

- La socialización, a través de talleres de las mejores prácticas de los auditores con mayor experiencia y resultado en las acciones de control y elaboración del correspondiente Informe Especial.

- Implementación de una norma o resolución más clara para la elaboración de los informes.

- Especializar a los que intervienen en la elaboración de los Informes Especiales.

- Elaborar un modelo oficial que explicite con mayor claridad y coherencia los pasos a seguir, así como el contenido a abordar en cada apartado del Informe Especial a presentar en el Grupo de Análisis. 
- Intercambio entre los sujetos que intervienen en el proceso investigativo (instructores, fiscales, auditores y peritos).

Los resultados que aportó la aplicación de esta técnica de la investigación se encuentran en correspondencia con los derivados del análisis de documentos. Ello sugiere la validez y confiabilidad del diagnóstico que hasta ahora indica que las causas que inciden en la insuficiente calidad de la elaboración del Informe Especial por la presunta comisión de un delito de Malversación no son esencialmente de orden normativo.

\section{C) Análisis Causa-Efecto}

De conformidad con los resultados obtenidos en las encuestas y el análisis de documentos, se consideró oportuna la identificación de las causas relacionadas con el problema objeto de estudio. Con este objetivo se realizó el diagrama de Ishikawa, causa-efecto o espina de pescado. Este constituye una herramienta de análisis que facilita la rápida visualización de las causas que originan un determinado efecto o problema. En su elaboración participaron especialistas o expertos directa o indirectamente relacionados con el problema. En este caso fueron consultados miembros del Grupo de Análisis del municipio y la provincia Santiago de Cuba y otros profesionales que por su labor tienen experiencia en el enfrentamiento y tramitación de los hechos vinculados al delito de Malversación; así como en la revisión y valoración del Informe Especial derivados de acciones de control en las que se detectan estos hechos.

Para el análisis se procedió, a través de una tormenta de ideas, a la identificación de las causas reales y potenciales que limitan la calidad del Informe Especial e impactan de forma negativa en la celeridad y efectividad de la tramitación y esclarecimiento del delito de Malversación. Como resultado, a través de la combinación del método de las $6 \mathrm{M}^{44}$ y el de enumeración de causas, ${ }^{45}$ se identificaron un conjunto de causas/subcausas. Después de considerar todas las aportadas se redujo la lista eliminando las redundantes o reagrupándolas y quedaron tres causas fundamentales: a) Dirección y organización, b) Recursos Humanos, c) Marco normativo.

Sobre estas también se definieron por consenso varias subcausas para un total de 16; a la vez constituyen barreras que afectan la calidad del Informe Especial. ${ }^{46} \mathrm{El}$ valor de los resultados radica en la posibilidad que brinda este método de adentrarse en las esencias de la problemática en pos de su solución.

44. El método las $6 \mathrm{M}$ es el más común para la elaboración del diagrama causa-efecto y agrupa las causas potenciales en seis ramas principales: método de trabajo, mano de obra, materiales, maquinarias, mediciones y medioambiente. $A A$. VV, Diplomado en Administración Pública. Compendio de lecturas de temas de Administración Pública, 187.

45. Este método va directamente a las principales causas potenciales de un problema. Sus ramas no siguen un esquema predeterminado como en el caso del método de las $6 \mathrm{M}$, pero requiere un mayor conocimiento acerca del problema y sus posibles causas. Vid. AA. VV, Diplomado en Administración Pública. Compendio de lecturas de temas de Administración Pública, 187.

46. Ver anexo no. 1. 
Con posterioridad, las causas fundamentales (espinas primarias) fueron ponderadas con el objetivo de conocer su importancia relativa respecto al efecto, lo que indica el orden de prioridad en relación a las soluciones y su nivel de influencia en el cambio pretendido. Mediante votación secreta cada especialista listó las causas por su orden de importancia, siendo la primera la más importante hasta el número tres como la menos importante.

Finalizadas las votaciones se sintetizaron en una tabla o matriz de ponderaciones donde Rj significa la sumatoria de los valores otorgados por cada uno de los especialistas (E); deduciendo de la $\mathrm{Rj}$ menor la causa más importante y de la $\mathrm{Rj}$ mayor la menos importante. ${ }^{47}$ En la matriz y diagrama de Ishikawa ponderado resulta "Recursos Humanos" como la causa más importante, seguida de la "Dirección y Organización” y finalmente el "Marco Normativo". ${ }^{48}$

El porcentaje de concordancia se determinó a través de la fórmula $\mathrm{C}=(1-\mathrm{Vn} / \mathrm{Vt})^{*} 100$, para determinar el nivel de consenso de los especialistas sobre el total de las causas mencionadas, donde: $\mathrm{C}$ es la concordancia expresada en porcentaje, Vn la cantidad de expertos en contra del criterio predominante y Vt la cantidad total de expertos participantes. Siempre que se alcance $\mathrm{C} \geq 60 \%$ para cada $\mathrm{Rj}$ se considera un buen nivel de consenso, como se aprecia en relación a las tres causas analizadas.

\section{PROPUESTAS PARA EL PERFECCIONAMIENTO DE LA PRESENTACIÓN DEL INFORME ESPECIAL}

El recorrido teórico-doctrinal realizado en torno al Informe Especial asociado a la probanza del delito de Malversación; así como la aplicación de los métodos y técnicas de la investigación utilizados, no solo permitió la fundamentación de la importancia de aquél como elemento de prueba en el contexto del proceso penal. También posibilitó la formulación de propuestas para su perfeccionamiento en función no solo del esclarecimiento de estos hechos, sino de lograr mayor celeridad en su tramitación, a la par que menos devoluciones de los Grupos de Análisis a los especialistas que realizan la acción de control de la que resultan estos informes.

A partir de la utilización de los postulados de la teoría del caso como herramienta doctrinal, las principales exigencias de la actividad probatoria y el tema probandum, se diseñaron un conjunto de pautas como sustento primordial para el proceso de presentación del Informe Especial. Estas vendrían a constituirse en una especie de norte a seguir por los contralores, auditores y especialistas que desarrollan acciones de control en las que advierten la presunta comisión de un delito de Malversación, viéndose conminados a la elaboración de dicho informe para su presentación al Grupo de Análisis correspondiente. Asimismo, muchas de estas pautas, en su integración pueden constituir la base de una futura metodología a ser empleada por estos sujetos como complemento de la vigente Resolución 480 de 2017.

47. Vid. Cuesta Santos, «La toma de decisiones consensuales: instrumentos y experiencias en gestión organizacional». 48. Ver anexo no. 2. 
En resumen, para la conformación de las pautas se utilizan directrices teórica-prácticas. La primera, empleada como fundamento en el cual se sustenta la investigación y la última, dirigida a la obtención de los criterios de los sujetos vinculados a la presentación y/o evaluación del Informe Especial en supuestos hechos de Malversación. La primera directriz permitió la elaboración del marco teórico, lo cual facilitó cumplir con las dos primeras etapas previstas para su conformación, la revisión de la literatura correspondiente y la adopción de una postura teórica. En esta dirección se integraron los enfoques teóricos, estudios y antecedentes generales que revelan las complejidades de la actividad probatoria. En tanto, la directriz práctica se condicionó al uso de las técnicas de encuesta y lluvia de ideas, así como a la aplicación del método de Ishikawa y el análisis de documentos. Como resultado, se obtienen conclusiones que se expresan a continuación y que constituyen la base de algunas de las pautas que se formulan. A saber:

a) Existe poco dominio en los especialistas de los elementos esenciales y necesarios para la conformación del Informe Especial.

b) Los juristas responsabilizados por razón de su cargo a revisar el Informe Especial, previa su presentación al Grupo de Análisis, no se encuentran debidamente preparados para ello.

c) El marco normativo que establece las exigencias para la presentación y tramitación del Informe Especial, aunque no es lo que más incide en la falta de calidad del mismo, es susceptible de perfeccionamiento a través de la elaboración de una metodología que lo complemente.

Finalmente, al vincular las dos directrices se conforma el conjunto de pautas que se proponen emplear como una herramienta de trabajo que coadyuve a un mejor y más eficaz desempeño de los profesionales que participan en la investigación de los delitos económicos en general y de la Malversación en particular. Estas pautas, en aras de una mejor comprensión de sus postulados, se dividen en tres grupos que responden a las causas que afectan la calidad de la presentación del Informe Especial según quedaron agrupadas en el diagrama causa-efecto, Ishikawa o espina de pescado.

\section{Primer grupo:}

\section{A. Relativas a los elementos del delito de Malversación que orientan la construcción de las proposiciones fácticas:}

1. Se trata de una conducta de defraudación consistente en invertir ilícitamente los bienes ajenos que el sujeto tiene a su cargo en usos distintos de aquellos para los que están destinados.

2. La conducta de defraudación recae sobre bienes de naturaleza económica, muebles o inmuebles objetos de propiedad, tenencia o posesión u otros derechos reales de esta naturaleza, ya sean bienes colectivos de organizaciones sociales y de masas, bienes de particulares al cuidado de una entidad económica e incluso de una entidad privada. 
3. Se requiere de la cualidad de funcionario del responsable directo (sujeto activo especial), significa que este ha de tener por razón del cargo que desempeńa la administración, cuidado o disponibilidad de bienes de propiedad estatal, o de propiedad de las organizaciones políticas; de masas o sociales, o de propiedad personal al cuidado de una entidad económica estatal, lo cual no implica la exigencia de que los tenga materialmente.

4. El sujeto no siempre lleva adelante personalmente la realización del hecho y en no pocas ocasiones se hace acompañar por otros sujetos que participan con acciones concretas.

5. La conducta lleva implícita el animus lucrandi, lo que significa que el responsable debe tener el ánimo de apoderarse de los bienes (animus rem sibihabendi). Se persigue la obtención de un beneficio o un enriquecimiento económico para el autor o un tercero, por lo que un tercero puede ser el beneficiado con la conducta.

6. En los casos que consienta que otro se apropie de los bienes dicho consentimiento tiene que ser la voluntad manifiesta del sujeto especial, que deja de realizar de manera consciente algunos de los deberes que le vienen impuestos por su función, para así permitir la apropiación por un tercero. En este supuesto se le imputa la responsabilidad por un resultado que el no produjo directamente, sino que permitió que se produjera, cuando él podía o debía evitarlo porque su omisión tiene la finalidad de que un tercero se apropie, por lo que tiene que estar de acuerdo con la apropiación.

7. El carácter de administrador tiene que darse cuando el sujeto, en función del cargo que ostenta está facultado administrativamente para disponer de los bienes, decidir sobre ellos. Significa que tiene como atribución legal el poder dar destinos correspondientes a los bienes, utilizar y distribuir estos según las normas que le han sido establecidas legalmente para su adecuada administración. En tanto el cuidado y vigilancia sobre los bienes lleva consigo su tenencia y se realiza como función administrativa. No es en modo alguno la mera actividad administrativa de vigilancia que realiza cualquier persona porque su puesto de trabajo tenga que ver con ello. La administración, la disponibilidad y la custodia deben haber sido confiadas al sujeto en razón del cargo que desempeńa, determinadas por disposiciones administrativas que otorgan competencia para realizarlas.

B. Relativas a la destreza del sujeto que realiza la acción de control, así como a la forma y/o calidad de la redacción del informe:

1. La habilidad del sujeto que realiza la acción de control en la redacción del Informe Especial es fundamental para que este logre sus objetivos y cumpla con los propósitos de ofrecer los elementos que permitan al destinatario conocer con claridad los resultados del trabajo realizado. Debe ser capaz de anticiparse a las interrogantes que puedan surgir y esforzarse para proporcionar las respuestas requeridas sin dejar margen a la duda. 
2. El Informe Especial debe contener información meticulosamente confiable, o sea, verificable, que pueda ser probada, demostrada; tener siempre en cuenta al redactar el informe a su destinatario y desglosar los hechos de lo particular a lo general. Las ideas deben tener conexión entre sí y ser concluidas.

3. El Informe debe ser oportuno, completo, exacto, objetivo y convincente, así como claro, conciso y fácil de entender. Como norma, todo lo que se consigne en él debe estar reflejado en los papeles de trabajo ${ }^{49}$ y responder a hallazgos relevantes con evidencias suficientes y competentes. Debe ser cuidadoso en los detalles, verificar las fuentes de información, comprobar las notas, citar los casos correctamente, utilizar los índices con eficiencia y manejar los números con facilidad y exactitud.

4. Las oraciones en el informe deben ser razonablemente breves y claras, evitando la monotonía. Los párrafos deben ser cortos y sugestivos para llevar al lector de uno a otro, sin perder la ilación. No se debe mencionar que se produjo un delito, solo se describe el presunto hecho delictivo pues corresponde a los tribunales decidir sobre ello.

\section{Relativas a la actividad probatoria:}

1. El dato o circunstancia que se pretende demostrar, debe cumplir con los requisitos de objetividad, legalidad, relevancia o utilidad y pertinencia. Así, por ejemplo, no toda la documentación primaria constituye un elemento de prueba. Para que el hecho o circunstancia sea objeto de prueba, deberá poseer una directa y significativa utilidad para el objeto de proceso, de modo que su determinación y fijación trascienda a la resolución de éste o para alcanzar cualquier otra finalidad procesal vinculada con el mismo.

2. Los auditores, contralores y especialistas que desarrollan la acción de control no deben conformarse con probar que realmente ha existido una defraudación de fondos. No hay que contentarse con identificar quién lo ha cometido, sino además determinar las circunstancias, el modus operandi cómo se ha producido. En el análisis contable se tiene que clarificar o esclarecer cuáles han sido los elementos de la operación y además el impacto económico e incluso el jurídico de la misma (principios, normas y métodos contables quebrantados). Hay que explicar en forma sencilla, lo que ha pasado, la normativa que había en vigor, cómo se documentó y lo que no debió pasar.

49. Papeles de trabajo $(\mathrm{P} / \mathrm{T})$, conforman el conjunto de documentos donde el auditor recopila, analiza y comenta la información y evidencias captadas en el transcurso de una auditoría. Son las vías de conexión entre los registros y documentos originales con el informe final de la auditoría. Además, constituyen la única prueba de exactitud de lo informado y soporte de dicho informe. Son las anotaciones, resúmenes y resultados de la investigación practicada por el auditor, evidencias y antecedentes formados por documentos de la propia entidad auditada o fotocopia de los mismos. Reflejan el alcance de la prueba realizada y período objeto de la verificación. Vid. Écheverría Hernández, Auditoría, 100-134. 
3. La determinación del medio de prueba a través de cual debe ingresar el Informe Especial al proceso penal dependerá de la previa precisión del elemento u órgano de prueba en el cual se visualiza la razón de suficiencia probatoria. Si del resto del material probatorio que se asocia al informe resulta claro el hecho y la intervención en el de los sujetos implicados, se puede usar como la tradicional prueba documental. Sin embargo, si este se presenta con contradicciones con el resto del material probatorio que deben someterse a debate para ganar en claridad en la construcción fáctica del hecho, entonces es aconsejable la intervención del perito para interrogarlo sobre su contenido y esclarecer tales contradicciones.

\section{Relativas a los requisitos y formalidades esenciales del Informe Especial:}

1. En el encabezamiento se precisarán los metadatos que establece el epígrafe 21.1 de la Resolución 480/2017 debiéndose incluir luego del inciso e) tipo de acción de control, un inciso que exija la consignación del periodo analizado [desde cuándo: (día, mes y año) y hasta cuándo (día, mes y año)]. Esto resulta de vital importancia para orientar el espacio temporal en el cual se circunscribe el presunto hecho delictivo. Sobre todo, cuando se trata, como en los supuestos de malversación, de delitos permanentes en los que debe tenerse especial cuidado de comprobar que el periodo que abarque la comisión de los hechos se encuentre comprendido dentro del cual su comisor fungió como responsable de la entidad afectada. Desde lo formal, al momento de la redacción se deben resaltar en negritas solo los subtítulos y nunca la información o datos consignados.

2. En la introducción que consta de tres elementos: caracterización de la entidad, objetivos trazados y breve descripción del presunto hecho delictivo, el redactor del informe debe separarlos por incisos o subtítulos y explicitar su contenido en el sentido que se expone a continuación:

a. Caracterización de la entidad: describir el objeto social del centro.

b. Objetivos trazados: se refiere a los propósitos perseguidos en la acción de control.

c. Breve descripción del presunto hecho delictivo: se trata de realizar una síntesis del hecho presuntamente delictivo, por cuanto su total descripción corresponde al desarrollo del informe. En este sentido debe hacerse referencia a los siguientes elementos: acción de control, entidad auditada, periodo analizado, irregularidad, afectación económica y sus responsables. Por ejemplo: En auditoría realizada a la Empresa Provincial de Gastronomía de Santiago de Cuba, específicamente al Almacén Central de Víveres, en el periodo comprendido del 1 ro de enero al 31 de diciembre de 2017, se detectaron treinta facturas ficticias que recogían los productos arroz, frijoles y azúcar, enviadas a tres unidades sin que se recepcionarán las mismas. Esto generó una afectación económica de 120310.00 CUP, siendo los máximos responsables directos Jorge Rodríguez Pérez y Julio Domínguez 
Estrada, quienes se desempeñaban como Encargado y Dependiente de Almacén, respectivamente. Asimismo, se determina como responsable colateral a José Pérez Guzmán, técnico en gestión económica.

3. El desarrollo del informe debe configurarse solo a través de la descripción detallada del hecho o conducta presuntamente delictiva, donde se precisan los elementos siguientes:

a. Cuándo ocurrió, especificando la fecha de ocurrencia del hecho o período en que se enmarca, consignando además la fecha de detección del presunto hecho delictivo.

b. Dónde ocurrió, refiriendo la entidad, organización superior de dirección empresarial, empresa, unidad empresarial de base, dependencia, establecimiento, organización, área de trabajo o forma de gestión no estatal donde se detectó el presunto hecho delictivo y la dirección donde se encuentra ubicada;

c. Cómo se cometió el hecho.

d. No debe faltar la descripción de manera cuidadosa de la documentación primaria revisada para ejecutar la acción de control en aras de una mejor comprensión del hecho por los instructores penales, fiscales y jueces. Estas deben ser los originales y archivarse de la misma forma o en el mismo orden en que se van refiriendo en el informe en aras de su mejor localización y comprensión, posibilitando la correspondencia del hecho descrito con las evidencias que lo sustentan. Cada elemento del relato del hecho debe tener un referente en la prueba que así lo demuestre. Es importante recalcar que se debe describir la conducta presuntamente delictiva no se califican los hechos, pues esto último corresponde a la Fiscalía y al Tribunal.

4. En la parte conclusiva del informe deben precisarse los siguientes subtítulos:

a. Modo de operar utilizado o el método empleado por los presuntos implicados.

b. Nombres y apellidos de los posibles implicados en el presunto hecho delictivo, en cuyo subtítulo debe mantenerse lo planteado en los incisos d) y e) de la Resolución 480/2017.Al describir las violaciones cometidas por esta persona y cuantificar la afectación económica causada, las imputaciones deben guardar relación con sus funciones según el calificador de cargo.

c. Cuantificación de los daños y perjuicios económicos ocasionados.

d. Disposiciones jurídicas, normas, procedimientos, estatutos y reglamentos vigentes, que se infringen o incumplen. 
e. Causas y condiciones que propiciaron la ocurrencia del presunto hecho delictivo, en cuyo subtítulo debe mantenerse lo planteado en los incisos h) e incluirse el contenido de los incisos i) y j) de la Resolución 480/2017.

f. Hacer referencia a las evidencias, que permiten determinar el hecho y sustentar el informe, en cuyo subtítulo debe mantenerse lo planteado en el inciso k) de la Resolución 480/2017.

5. En la parte final del informe debe mantenerse lo establecido en los epígrafes 21.2.3, 21.3 21.4 y 21.5 de la Resolución 480/2017. No obstante, adicionamos el requisito de sellar cada hoja en el borde inferior derecho y refrendarlo con su firma.

Segundo grupo: Pautas asociadas a la superación de los recursos humanos que intervienen en la elaboración y presentación del Informe Especial.

Estas pautas obedecen a la necesidad de implementar un programa de formación para los sujetos que participan en la elaboración y presentación del Informe Especial al Grupo de Análisis, con especial énfasis en los contralores, auditores y especialistas que realizan la acción de control. No obstante, también puede dirigirse a los instructores penales y fiscales que tramitan los presuntos hechos de Malversación para su presentación al Tribunal competente. Esta propuesta tiene la misión de garantizar la calidad del Informe Especial derivado de la presunta comisión de este ilícito penal, a partir de la mejor compresión de sus elementos de forma y contenido. Asimismo, el desarrollo de las habilidades necesarias en torno a los aspectos más técnicos de esta actividad.

Las pautas para el diseño del programa se sustentan, no solo en función de las normativas que rigen los requisitos y formalidades esenciales del Informe Especial. También se tienen en cuenta las necesidades de los sujetos responsables de su elaboración y presentación. Todos los relacionados con esta actividad deben formarse por lo que no se excluirán los directivos encargados de su gestión y control.

En esta trayectoria juega un importante rol el diagnóstico realizado sobre las principales irregularidades que motivan las devoluciones del Informe Especial por parte del Grupo de Análisis a los sujetos que realizan la acción de control. También, la información aportada del estudio de las encuestas y el criterio de los expertos o especialistas sistematizado en el diagrama causa-efecto. Todo este procesamiento permitió la identificación de aquellas insuficiencias cuya causa radica en el desconocimiento de las principales coordenadas de la actividad probatoria, los elementos fácticos del delito de Malversación y la vaguedad de algunos conceptos empleados por el redactor de la Resolución 480/2017. Bajo estos presupuestos, los temas que se definen como necesarios son:

- El delito de Malversación: análisis de los elementos del tipo penal

- La actividad probatoria en el proceso penal: un análisis ineludible

- La importancia de la prueba pericial económica: experiencia comparada 
- Los órganos de control y fiscalización de la economía de cara al proceso penal en Cuba

- El Informe Especial sobre presunto hecho delictivo: principales coordenadas

- El Informe Especial en los casos de malversación. Principales problemáticas

- Propuestas para el perfeccionamiento de la presentación del Informe Especial

Varios son los métodos, formas o modalidades que adopta la formación, pero se recomienda la figura de cursos de posgrados y/o entrenamientos, así como la realización de talleres o seminarios con un carácter más específico. En relación a la evaluación del impacto del programa de formación se apuesta por su valoración a partir de la disminución de las devoluciones del Informe Especial por parte del Grupo de Análisis a los sujetos que realizan la acción de control; así como de las que realiza la Fiscalía y el Tribunal. Asimismo, de forma periódica se propone la revisión del programa, elaborarán informes de resultados y realizará el análisis del nivel de satisfacción de los participantes del curso.

Para conocer el nivel de satisfacción de los cursistas se propone la utilización de la técnica Iadov. Esta técnica creada en su versión original por V. A. Iadov para evaluar la satisfacción de los estudiantes por las carreras pedagógicas, ha sido reformulada por muchos autores con el mismo fin, pero en diferentes contextos. ${ }^{50}$ Con el objetivo de calcular el Índice de Satisfacción Grupal (ISG) se implementa mediante una encuesta en la cual se le incluyen cinco preguntas: tres cerradas y dos abiertas que se intercalan dentro de un total de interrogantes que contiene el cuestionario y cuya relación él encuestado desconoce. De la encuesta que se propone, ${ }^{51}$ las preguntas cerradas son la 1,3 y 5 en tanto las preguntas abiertas son la 2 y 4 .

Estas preguntas se relacionan a través del "Cuadro Lógico de Iadov" el cual permite ubicar a cada encuestado en una escala de satisfacción para luego calcular el ISG. El número resultante de la interrelación de las tres preguntas indica la posición de cada sujeto en la escala de satisfacción, o sea, su satisfacción individual. La escala utilizada es la siguiente: Clara satisfacción (1). Más satisfecho que insatisfecho (2). No definida (3). Más insatisfecho que satisfecho (4). Clara insatisfacción (5). Contradictoria (6).

El "Cuadro Lógico de Iadov" tiene una configuración invariable de filas y columnas, en cuyas intersecciones se han colocado valores que representan los niveles de satisfacción que pueden obtenerse para cada encuestado. Las preguntas de interés que se diseñan como preguntas cerradas se colocan en las celdas correspondientes teniendo en cuenta el interés del encuestador y las características de este instrumento, en el que la máxima satisfacción (valor 1) se obtiene respondiendo "NO" a la primera pregunta, "SI" a la segunda y "Me gusta mucho" a la tercera. Por otra parte, la máxima insatisfacción (valor 5) se obtiene respondiendo "SI" a la primera pregunta, "NO" a la segunda y "No me gusta nada" a la tercera.

50. Alfonso Pérez y Serra Toledo, «Análisis de la orientación educativa en la formación del ingeniero civil»; López Rodríguez y González Maura, «La técnica de Iadov. Una aplicación para el estudio de la satisfacción de los alumnos por las clases de educación física».

51. Ver modelo de encuesta en anexo no. 3. 
Por ejemplo: si un encuestado responde a la pregunta No. 1 "NO", vamos a la zona izquierda del cuadro, debajo de la pregunta No. 1, donde aparece "NO". Si a la pregunta No. 3 responde "No SÉ" buscamos el "NO SÉ" que aparece debajo del "NO" anterior. Si a la pregunta No. 5 responde: "Me disgusta más de lo que me gusta" entonces buscamos en las filas, a la izquierda, la casilla donde aparece esa respuesta y buscamos el punto donde se interceptan la fila "Me disgusta más de lo que me gusta" con la columna "NO SÉ". El resultado de dicho trabajador es "3," que equivale a "satisfacción no definida". Así se procede con cada encuestado en dependencia de sus respuestas a dichas preguntas. De esta forma se irán clasificando en las " 6 " categorías antes mencionadas.

Para obtener el índice se trabaja con los diferentes niveles de satisfacción que se expresan en una escala numérica con valores que oscilan entre +1 y -1 de la siguiente forma: $(+1)$ Máximo de satisfacción, $(0,5)$ Más satisfecho que insatisfecho; (0) No definido y/o contradictorio; $(-0,5)$ Más insatisfecho que satisfecho; (-1) Máxima insatisfacción.

Luego el ISG se calcula por la fórmula que se ilustra a continuación, donde A, B, C, D y E, representan el número de encuestados con índice individual correspondiente al valor entre paréntesis y $\mathrm{N}$, el de la muestra.

$\frac{\mathrm{ISG}=(\mathrm{A}(+1)+\mathrm{B}(+0,5)+\mathrm{C}(0)+\mathrm{D}(-0,5)+\mathrm{E}(-1))}{\mathrm{N}}$

La interpretación final de los resultados del ISG obtenido se muestra en el anexo 4 en el que también se ilustra cómo se puede apreciar de forma gráfica. También se hará uso de la entrevista grupal con el fin de conocer las ideas, criterios y valoraciones de los cursistas con el programa de formación.

Tercer grupo: Pautas de orden directivo u organizacional.

1. Las devoluciones fundamentadas en deficiencias en la elaboración del Informe Especial, en principio, constituyen manifestaciones de errores en el trabajo y hay que valorarlas críticamente como tales.

2. El establecimiento de un sistema de despacho del correspondiente jefe administrativo del controlador, auditor o especialista que desarrolla la acción de control con el objetivo de:

3. Dar seguimiento al proceso de elaboración y presentación del Informe Especial derivado de la presunta comisión de un delito de Malversación.

4. Dar seguimiento al proceso de subsanación de las irregularidades detectadas por el correspondiente Grupo de Análisis al Informe Especial presentado y que motivaron su devolución al controlador, auditor o especialista que desarrolla la acción de control. 
5. Exigir el dictamen del Informe Especial por parte del jurista responsabilizado previo a su presentación al Grupo de Análisis.

6. Aplicar el reglamento disciplinario en aquellos casos que la falta de calidad y oportuna presentación del Informe Especial al Grupo de Análisis obedezca a negligencia o imprudencia del controlador, auditor o especialista que desarrolla la acción de control.

Hasta aquí se ha tratado de acotar las pautas con las cuales tributar al perfeccionamiento del Informe Especial resultado de las acciones de control en que se detecte un presunto hecho delictivo de Malversación, si bien pudieran tenerse en cuenta para otros delitos de naturaleza económica. La mesura y la reflexión han marcado los senderos de éste iter investigativo, y una vez desarrollada la perspectiva teórica y valorativa que sostenemos para lograr los resultados propuestos, solo nos resta afirmar, al lado de uno los principales cultores del Derecho Penal de estos tiempos: "El Derecho penal tiene que mantener la vinculación con el cambio social: tiene que estar preparado para dar respuesta a las preguntas de hoy (...). Tiene que seguir evolucionando en contacto con su realidad" 52 .

\section{CONCLUSIONES}

La Malversación es un delito pluri ofensivo, de carácter permanente y sujeto especial impropio. Constituye una conducta defraudadora que recae sobre bienes de naturaleza económica bajo la administración, cuidado o disponibilidad del sujeto activo, quien no siempre lleva adelante personalmente la realización del hecho, y en no pocas ocasiones se hace acompañar por otros sujetos que participan con acciones concretas en su realización. Su ejecución persigue la obtención de un beneficio o enriquecimiento económico (animus lucrandi), para el autor o un tercero. Dada sus características típicas su esclarecimiento reviste especial dificultad requiriéndose de saberes especializados para su probanza.

En el esfuerzo de incorporar los rastros que conducen a la demostración de la comisión del delito de Malversación, la prueba documental y la pericia económica constituye parte esencial del procedimiento. Las especiales características del Informe Especial imprimen complejidad al decidir el medio de prueba a emplear para su ingreso al proceso penal, acentuándose por ello la necesidad de observar las exigencias del tema probandum para asegurar su admisión por el Tribunal.

El Informe Especial sobre presunto hecho delictivo resultado de una acción de control deviene en el contexto del proceso penal cubano en instrumento probatorio para ser conocido por el Tribunal. A pesar de su importancia en la probanza del delito de Malversación persisten dificultades en su elaboración y presentación que demoran estos procesos e inciden en el número de devoluciones del Grupo de Análisis a sus redactores para su corrección y/o ampliación.

52. Hassemer, «La ciencia jurídico penal en la República Federal Alemana», 79. 
En el diagnóstico realizado a los sujetos que intervienen en la elaboración del Informe Especial se detectaron deficiencias que fueron sistematizadas durante la investigación en tres grupos: relativas a los "Recursos Humanos" como las más importantes, seguidas de la de "Dirección y Organización” y finalmente asociadas al "Marco Normativo", las que inciden negativamente en la calidad del referido instrumento.

El desarrollo de acciones para evaluar el índice de satisfacción grupal constituye un importante instrumento de trabajo a través del cual es posible medir los resultados de las acciones de superación desarrolladas sobre temáticas complejas como las que derivan del tratamiento a los delitos que afectan la economía.

El estudio realizado reveló la necesidad de la conformación de pautas que tributen al perfeccionamiento de la elaboración y presentación del Informe Especial, en aras de contribuir con el esclarecimiento y celeridad de los proceso penales incoados por la presunta comisión del delito de Malversación. Una propuesta contentiva de esta misiva es la que se aporta en este trabajo con una adecuada estructuración en tres grupos de las pautas en correspondencia con las deficiencias que fueron diagnosticadas.

- Primer grupo: pautas de orden teórico-metodológico.

- Segundo grupo: Pautas asociadas a la superación de los recursos humanos que intervienen en la elaboración y presentación del Informe Especial.

- Tercer grupo: Pautas de orden directivo u organizacional.

\section{REFERENCIAS}

- AA.VV. Diplomado en Administración Pública. Compendio de lecturas de temas de Administración Pública. Escuela Superior de Cuadros del Estado y del Gobierno, 2015.

- $\quad$ Alfonso Pérez, Ibette, y Rolando Serra Toledo. «Análisis de la orientación educativa en la formación del ingeniero civil». Revista Cubana de Ingeniería IV, n.o 2 (agosto de 2013): 13-18.

- Baratta, Alessandro. Criminología crítica y crítica del derecho penal: introducción a la sociología jurídico penal. 1 ra reimp. Buenos Aires: Siglo XXI Editores Argentina, s. f.

- Cervini, Raúl. «Derecho penal económico, perspectiva integrada». Portal del Centro de Investigación Interdisciplinaria en Derecho penal económico, 2011. www.ciidpe.com.ar.

- «Constitución de la República de Cuba», 10 de abril de 2019. http://www.cubadebate.cu/noticias/2019/04/09/descargue-la-constitucion-de-larepublica-de-cuba-pdf/. 
- Contraloría General de la República. «Resolución No. 480/2017». Ministerio de Justicia. Gaceta Oficial de la República de Cuba. Gaceta Oficial No. 59 Extraordinaria, 15 de diciembre de 2017.

- $\quad$ Cook y Winkle. Auditoría. Vol. 1. 2 vols. La Habana: Editorial Félix Varela, 2006.

- Cuba. Asamblea Nacional del Poder Popular. «Ley No. 83 "De la Fiscalía General de la República”", 11 de julio de 1997.

- _ _Ley No. 107 “De la Contraloría General de la República de Cuba”. Gaceta Oficial No. 029 Extraordinaria de 14 de agosto de 2009, 1 de agosto de 2009.

- Cuba. Comité Ejecutivo del Consejo de Ministros. «Acuerdo no. 4045. “Objetivo, funciones, atribuciones específicas y estructura del Ministerio de Auditoría y Control"”, 31 de mayo de 2001.

- Cuba. Consejo de Estado. «Acuerdo. Reglamento de Ley No. 107 “De la Contraloría General de la República de Cuba”». Gaceta Oficial No. 032 Extraordinaria de 22 de noviembre de 2010, 30 de septiembre de 2010.

- _ _. «Decreto Ley No. 219 "Del Ministerio de Auditoría y Control”». Gaceta Oficial Ordinaria No. 20, de fecha 03/07/1995, 21 de abril de 2001.

- _ _. «Decreto-Ley No. 159. De la Auditoría», 8 de junio de 1995.

- Cuba. Contraloría General de la República de Cuba. «Resolución No. 60 “Normas del Sistema de Control Interno"». Gaceta Oficial No. 013 Extraordinaria de 3 de marzo de 2011, 1 de marzo de 2011.

- _ _ _Resolución No. 480 “Procedimiento para la tramitación del Informe Especial en las acciones de control en que se detecte un presunto hecho delictivo y en las solicitadas por los Tribunales Populares, la Fiscalía general de la República y el Ministerio del Interior”». Gaceta Oficial No. 59 Extraordinaria de 15 de diciembre de 2017, 4 de diciembre de 2017.

- Cuba. Ministerio de Auditoría y Control. «Resolución No. 248 "Procedimiento para la Elaboración, Presentación, Tramitación del Informe Especial sobre presunto hecho delictivo y Seguimiento de las acciones para su esclarecimiento y procesamiento, cuando se detectan en las acciones de control que realizan los auditores del Sistema Nacional de Auditoría"”. Publicada en la Gaceta Oficial Ordinaria No. 70, de fecha 26/10/2007, 25 de septiembre de 2007.

- _ _ _ _Resolución No. 320 "Procedimientos para la presentación y tramitación del Informe Especial”», 20 de octubre de 2003. 
- Cuesta Santos, Armando. «La toma de decisiones consensuales: instrumentos y experiencias en gestión organizacional». Universidad Tecnológica de La Habana. Accedido 5 de octubre de 2018. http://www.revistadyo.com/index.php/dyo/article/view/283/283.

- De la Cruz Ochoa, Ramón. Crimen Organizado, Tráfico de Drogas, Lavado de Dinero y Terrorismo. La Habana: Editorial de Ciencias Sociales, 2004.

- _. «Delitos contra la economía nacional». En Derecho Penal Especial, I:225-52. La Habana: Félix Varela, 2003.

- Durkheim, Emile. La División del Trabajo Social y el Suicidio. París: PUF, 1991.

- Écheverría Hernández, Rogelio. Auditoría. Ciudad de La Habana: Editorial Pueblo y Educación, 2002.

- Grillo Longoria, José Antonio. Los delitos en especie. Vol. I. 2 vols. La Habana: Editorial de Ciencias Sociales, 1982.

- Hassemer, Winfried. «La ciencia jurídico penal en la República Federal Alemana». Anuario de Derecho Penal y Ciencias Penales XLVI, n.o Fascículo I (abril de 1993).

- $\quad$ King Merton, Robert. Teoría Social y Estructura Social. New York: The Free Press, 1968.

- López Rodríguez, Alejandro, y Viviana González Maura. «La técnica de Iadov. Una aplicación para el estudio de la satisfacción de los alumnos por las clases de educación física». Revista Digital Año 8, n.o 47 (abril de 2002). http://www.efdeportes.com/.

- $\quad$ Maquiavelo, Nicolás. El Príncipe. La Habana: Editorial Félix Varela, 1996.

- Mata Barranco, Roberto J. de la, Jacobo Dopico Gómez-Aller, Juan Antonio Lascuraín Sánchez, y Adán Nieto Martín. Derecho penal económico y de la empresa. Madrid: Editorial Dykinson, 2018.

- Mejías Rodríguez, Carlos Alberto. Derecho Penal Económico. La Habana: Editorial Félix Varela, 2016.

- Navarro Borges, Vinmaris. «El informe especial. Utilidad probatoria para el delito de malversación». Tesis de especialidad, Universidad de Oriente, 2012.

- $\quad$ Rivero García, Danilo. Ley de Procedimiento Penal, Ley no. 5 de 13 de agosto de 1977 (Anotada y concordada con las Disposiciones del CGTSP). 2a edición. La Habana: Ediciones ONBC, 2012. 
- Rodríguez Carrazana, Maris Leydis. «El Informe Especial. Su repercusión en la actividad probatoria en los delitos económicos». Tesis de especialidad, Universidad de Oriente, 2015.

- Sokol, Natalia. Búsqueda y recuperación de la información. La Habana: Editorial Félix Varela, 2004.

- Tiedemann, Klaus. «Abuso del poder económico y comercio internacional. Dos problemas básicos de la delincuencia económica». Separata de la Revista del Derecho Industrial. Ediciones Depalma, Buenos Aires 8 (1981).

RECIBIDO:08/02/2021

APROBADO: $10 / 27 / 2021$ 


\section{Anexo No. 1. Diagrama Ishikawa o causa-efecto}

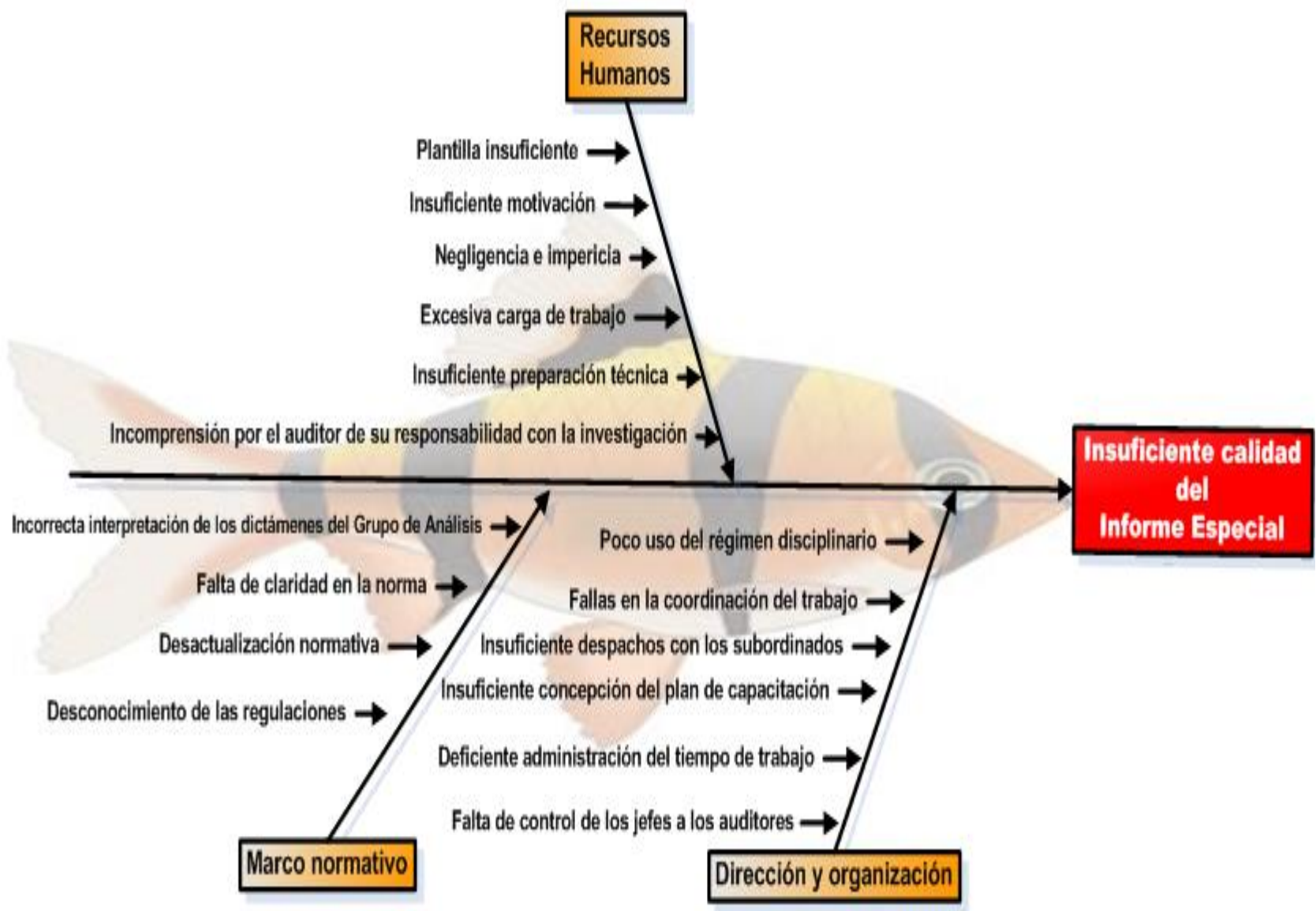

\section{Anexo No. 2. Matriz y Diagrama de Ishikawa ponderado}

\begin{tabular}{|l|l|l|l|l|l|l|l|l|l|l|l|l|l||}
\hline No. EXPERTOS (E) Causas & E1 & E2 & E3 & E4 & E5 & E6 & E7 & E8 & E9 & E10 & E11 & Rj & C \\
\hline 1. Dirección y organización & 2 & 2 & 3 & 2 & 2 & 3 & 2 & 2 & 3 & 1 & 2 & 24 & $64 \%$ \\
\hline 2. Recursos Humanos & 1 & 1 & 1 & 1 & 1 & 2 & 1 & 1 & 2 & 3 & 1 & 15 & $73 \%$ \\
\hline 3. Marco Normativo & 3 & 3 & 2 & 3 & 3 & 1 & 3 & 3 & 1 & 2 & 3 & 27 & $64 \%$ \\
\hline
\end{tabular}




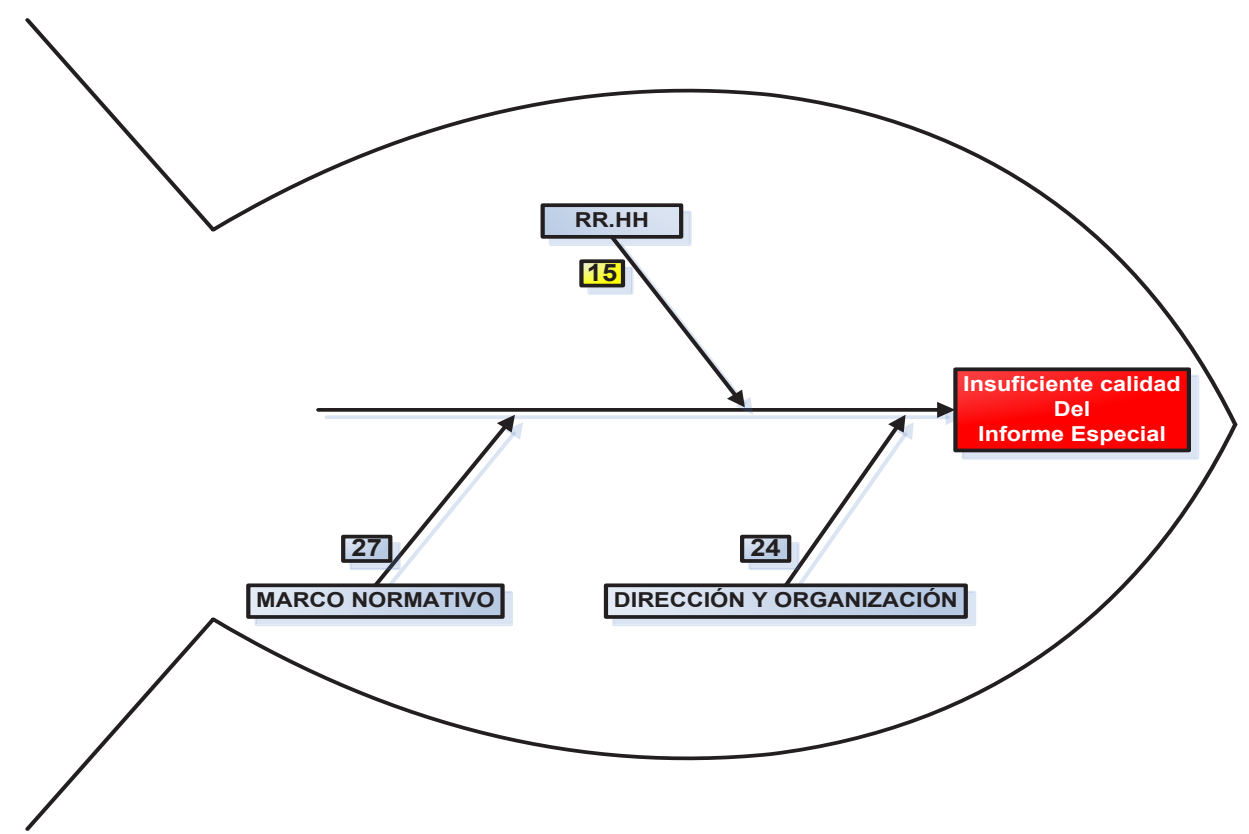

\section{Anexo No. 3. Propuesta de encuesta para conocer el nivel de satisfacción con el programa de}

\section{formación}

Estimada(o) compañera(o), Ud., ha concluido el programa de formación relacionado con la elaboración del Informe Especial. Le pedimos que dedique unos minutos a responder esta encuesta que tiene como objetivo conocer el nivel de satisfacción que se ha logrado con el curso. La encueta es anónima y de antemano le agradecemos la franqueza con la que responderás las preguntas.

\section{I.- DATOS GENERALES}

I.I.- Sexo:

Femenino Masculino

Edad:

I.II.- Nivel educacional:

Técnico Medio___Universitario

I.III. - Labor que desempeña 
I.IV.- Años de experiencia en la actividad

1.- ¿Hubieras deseado recibir la formación en una temática diferente?

Sí__NO_.NO SÉ

2.- ¿Qué es lo que más le ha gustado del curso?

3.- ¿Hubiera deseado hacer otra cosa en el horario establecido para este curso de superación sobre la elaboración del Informe Especial?

Sí_No__.NO SÉ

4.- ¿Qué es lo que más le ha disgustado del curso?

5.- ¿Qué considera del curso en el que acabas de participar? (Escoja solo una de las respuestas).

Me gustan mucho

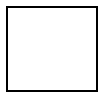

Me gustan más de lo que me disgustan

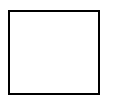

Me dan lo mismo

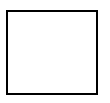

Me disgustan más de lo que me gustan

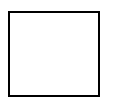

No me gustan

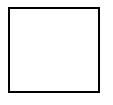

No sé qué decir

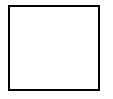


Anexo No. 4. Cuadro lógico de ladov con preguntas formuladas y representaciones gráficas del ISG

\begin{tabular}{|c|c|c|c|c|c|c|c|c|c|}
\hline \multirow{4}{*}{$\begin{array}{l}\text { 5.- ¿Qué considera del } \\
\text { curso en el que acabas de } \\
\text { participar? }\end{array}$} & \multicolumn{9}{|c|}{ 1.- ¿Hubieras deseado recibir la formación en una temática diferente? } \\
\hline & \multicolumn{3}{|c|}{ sí } & \multicolumn{3}{|c|}{ NO SÉ } & \multicolumn{3}{|c|}{ NÓ } \\
\hline & \multicolumn{9}{|c|}{$\begin{array}{l}\text { 3.- ¿Hubiera deseado hacer otra cosa en el horario establecido para este curso } \\
\text { de superación sobre la elaboración del Informe Especial? }\end{array}$} \\
\hline & SI & NO SÉ & NO & SI & NO SÉ & NO & SI & NO SÉ & NO \\
\hline Me gusta mucho & 1 & 2 & 6 & 2 & 2 & 6 & 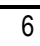 & 6 & 6 \\
\hline $\begin{array}{l}\text { Me gusta más de lo que me } \\
\text { disgusta }\end{array}$ & 2 & 2 & 3 & 2 & 3 & 3 & 6 & 3 & 6 \\
\hline Me es indiferente & 3 & 3 & 3 & 3 & 3 & 3 & 3 & 3 & 3 \\
\hline $\begin{array}{l}\text { Me disgusta más de lo que } \\
\text { me gusta }\end{array}$ & 6 & 3 & 6 & 3 & 4 & 4 & 3 & 4 & 4 \\
\hline No me gusta & 6 & 6 & 6 & 6 & 4 & 4 & 6 & 4 & 5 \\
\hline No puedo decir & 2 & 3 & 6 & 3 & 3 & 3 & 6 & 3 & 4 \\
\hline
\end{tabular}

Fuente: Elaboración propia

\begin{tabular}{|c|c|}
\hline Valores del ISG en el intervalo & Interpretación \\
\hline-1 hasta $-0,5$ & Insatisfacción \\
\hline$-0,49$ hasta $+0,49$ & Contradicción \\
\hline 0,5 hasta 1 & Satisfacción \\
\hline
\end{tabular}

Rango de valores y nivel de satisfacción

Fuente: Elaborado a partir deAlfonso Pérez et al., 2013

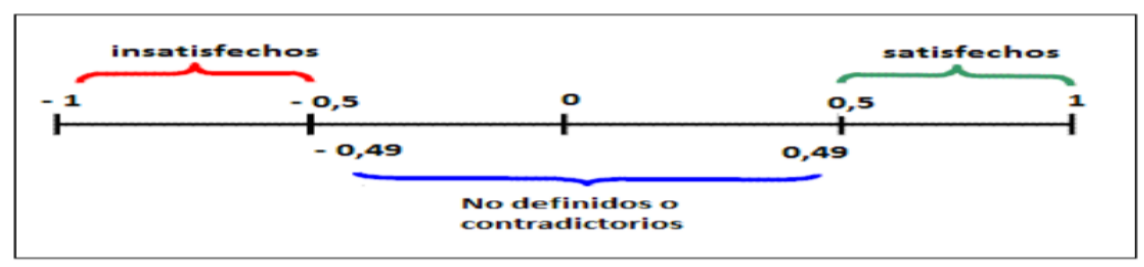

Representación gráfica de los niveles de satisfacción grupal

Fuente: Alfonso Pérez et al., 2013 